\title{
Integrated 3-D stress determination by hydraulic fracturing in multiple inclined boreholes beneath an underground cavern
}

\author{
Joong-Ho Synn ${ }^{\mathrm{a}, \mathrm{d},{ }^{*}}$, Chan Park ${ }^{\mathrm{a}}$, Yong-Bok Jung ${ }^{\mathrm{a}}$, Choon Sunwoo ${ }^{\mathrm{a}}$, Ki-Seog Kim ${ }^{\mathrm{b}}$, \\ Si-Young Choi ${ }^{\mathrm{b}}$, Myung-Kyu Song ${ }^{\mathrm{c}}$, Il-Jae Shin ${ }^{\mathrm{c}}$, Jonny Rutqvist ${ }^{\mathrm{d}}$
}

${ }^{a}$ Korea Institute of Geoscience and Mineral Resources (KIGAM), 124 Gwahang-no, Yuseonggu, Daejeon, 305-350 Korea

${ }^{\mathrm{b}}$ Heesong Geotek Co., LTD, 146-8 Sangdaewon-dong, Jungwon-gu, Seongnam-city, Gyeonggi Province, Korea

${ }^{\mathrm{c}}$ Hyundai Engineering \& Construction Co., LTD, 75 Yulgongno, Jongno-gu, Seoul, 110-920 Korea

${ }^{\mathrm{d}}$ Lawrence Berkeley National Laboratory (LBNL), Berkeley, CA 94720, USA

* Corresponding author: Joong-Ho Synn

Underground Space Department, Geologic Environment Division,

Korea Institute of Geoscience and Mineral Resources

124 Gwahang-no, Yuseong-gu, Daejeon, 305-350 Korea

Tel.: +82-42-868-3242, Fax.: +82-42-868-3416

E-mail address: jhsynn@kigam.re.kr (Joong-Ho Synn)

\section{ABSTRACT}

This paper presents a complete three-dimensional stress determination using hydraulic fracturing data from three inclined boreholes, drilled from the floor of an underground cavern at a depth of about $100 \mathrm{~m}$. Both conventional hydraulic fracturing (HF) and hydraulic testing of pre-existing fractures (HTPF) were carried out at all test points to acquire reliable data and conduct the integrated stress 
analysis. We determined 3-D stress states using a numerical inversion code that integrates the entire data set from HF and HTPF methods, and employs a nonlinear least-squares optimization routine based on a modified Levenberg-Marquardt method and a finite-difference Jacobian algorithm. We present the trend of complete three-dimensional stress states, with depth expressed by correlation equations. We compare the 3-D stress inversion result for the integration of all data from the three boreholes with the results determined independently for each individual borehole. The results showed that the maximum principal stress was subhorizontal and oriented approximately NNE-SSW, and the ratio of maximum to minimum principal stress was 2.0 on average. The inverted scatter of misfit remained within $10 \%$ for both the integrated analysis of the entire data set and the measurement data for each individual borehole. From these findings, we conclude that the 3-D stress determination made by integration of HF and HTPF data from multiple inclined boreholes resulted in a reliable inversion of the 3-D stress field.

\section{Keywords}

Hydraulic fracturing, Pre-existing fracture, Multiple inclined boreholes, Integrated 3-D stress inversion, Scatter analysis

\section{Introduction}

With underground space utilization, such as for underground energy storage and nuclear waste disposal), calling for larger rock caverns at increasing depth, a thorough understanding of a rock formation's in situ stress state is critical for optimum design and safe maintenance of underground facilities. Hydraulic fracturing is known as a powerful technique for in situ stress measurement. It has the advantage of not requiring knowledge of the elastic properties of a given rock mass, because the stresses are directly measured at the test location [1,2]. Stephansson and Zang reported an overall review of rock stress models and rock stress estimation methods [3], which explains the historical advance of hydraulic fracturing technique (HF and HTPF) and integrated stress determination method. Hydraulic testing of preexisting fractures (HTPF) as an alternative to the conventional HF has developed in the early 1980s [4, 5]. Cornet presented the HTPF stress determination method together with the integrated stress determination method [6].

Since the theory of hydraulic fracturing for stress measurement was first suggested by Hubbert \& Willis [7], significant research has been conducted on the subject, including analyses of factors such as rock permeability [8-10] and pre-existing fractures [11-15], the methodologies of stress analysis such as the fracture-mechanics approach [16], and numerical simulation of fracture behavior. However, most research related to hydraulic fracturing stress measurements has been limited to two-dimensional approaches, using vertical boreholes. 
Three-dimensional stress measurement using hydraulic fracturing (HF) was suggested in the late 1980s [17, 18] and has advanced with the integration of HF and HTPF, though mostly in vertical boreholes [19-22]. Three-dimensional stress measurement using arbitrary inclined boreholes has also been studied, in theory and in laboratory scale tests [17, 23], as well as in the field [18, 24]. However, these field applications [18, 24] were based on conventional HF only and had restriction in fully 3-D stress determination. Stress measurements using inclined boreholes are still not common, and to the authors' knowledge, studies of 3-D stress determination by integrating HF and HTPF in multiple inclined boreholes have not been reported.

In conventional HF stress measurement, the main parameters evaluated in field testing are the fracture reopening pressure and fracture shut-in pressure $[2,25]$. These pressure parameters are related to coupled fluid pressure and fracture mechanical behavior in opening and closing stages. The values for these parameters are commonly determined from pressure versus time records obtained by conventional $\mathrm{HF}$, or sometimes from pressure and flow rate versus time records obtained by HTPF, using statistical or graphical techniques [26-28]. There have been many studies on the uncertainties in interpreting pressure records and fracture patterns [13, 29-31]. These pressure parameters should be carefully determined and applied to the proper governing equation of the stress analysis, depending on the fracture trace pattern at the test point $[13,32]$.

In this study, we carried out a three-dimensional stress measurements, using hydraulic fracturing data from three inclined boreholes drilled from the floor of an underground cavern at a depth of $\sim 100 \mathrm{~m}$. At the site, both conventional HF and HTPF were carried out for all test points to acquire reliable data and to carry out the integrated stress analysis. Fracture traces on the borehole wall of test points were investigated before and after the test, using an acoustic borehole televiewer. We then determined the 3-D stress field using a numerical inversion code that integrates the entire data set from HF and HTPF, and employs a nonlinear least-squares optimization routine based on a modified Levenberg-Marquardt method and a finite-difference Jacobian algorithm for solving multivariable nonlinear equations [33]. We present depth trends for the complete three-dimensional stress field expressed by correlation equations, noting the scatter and reliability of the stress determination through misfit analysis. Finally, we compare the stress state determined by the integration of all data from three boreholes with the stress states determined independently for each individual borehole. 


\section{Principle of integrated 3-D stress determination by hydraulic fracturing and hydraulic testing of pre-existing fractures}

\subsection{Governing equations in 3-D stress analysis}

In conventional HF or HTPF using arbitrary inclined boreholes, two types of fractures can be expected, depending on the initial stress state and the borehole orientation: (a) A longitudinal fracture, with its plane parallel to the borehole axis. (b) A transverse fracture, with its plane inclined to the borehole axis.

The state of stress at the borehole wall and the fracture plane is redistributed differently, depending on the fracture type. Therefore, the governing equations for 3-D stress determination also differ, depending on the fracture type.

The governing equations for 3-D stress analysis can be derived from elasticity theory, using a geometric system of interrelationship among coordinates, boreholes, and fractures [17, 23, 34]. Figure 1 shows the configuration of coordinate systems that we adopt in this study to express the geometric relationship between boreholes and fractures. The $N-E-V$ coordinate represents the azimuth of north, east, and vertical direction; the $X-Y-Z$ coordinate is related to borehole geometry; and the $x-y-z$ coordinate is related to fracture geometry. The stress components $\left(S_{X}, S_{Y}, S_{X Y}\right)$ in the $X-Y-Z$ coordinate are expressed with the stress components $\left(S_{N}, S_{E}, S_{V}, S_{N E}, S_{E V}, S_{V N}\right)$ in the azimuth coordinate as

$$
\begin{gathered}
S_{X}=S_{N} \cos ^{2} \alpha \cos ^{2} \beta+S_{E} \sin ^{2} \alpha \cos ^{2} \beta+S_{V} \sin ^{2} \beta \\
+S_{N E} \sin 2 \alpha \cos ^{2} \beta+S_{E V} \sin \alpha \sin 2 \beta+S_{V N} \cos \alpha \sin 2 \beta \\
S_{Y}=S_{N} \sin ^{2} \alpha+S_{E} \cos ^{2} \alpha-S_{N E} \sin 2 \alpha \\
S_{X Y}=-0.5\left(S_{N}-S_{E}\right) \sin 2 \alpha \cos \beta+S_{N E} \cos 2 \alpha \cos \beta-S_{E V} \cos \alpha \sin \beta+S_{V N} \sin \alpha \sin \beta
\end{gathered}
$$

where $\alpha$ is the inclination of the borehole from the $N$-axis, $\beta$ is the inclination of the borehole from the $V$ axis, and $\theta$ is the direction of the fracture from the $X$-axis.

In the case of a longitudinal fracture (Fig. 1a), two governing equations can be derived considering the relationship between the in situ stress field and the fluid pressures within the borehole or inside the fracture $[17,23,34]$. The two governing equations, expressed as

$$
\begin{aligned}
& P_{r}=S_{X}\left(3 \sin ^{2} \theta-\cos ^{2} \theta\right)-S_{Y}\left(3 \cos ^{2} \theta-\sin ^{2} \theta\right)-4 S_{X Y} \sin 2 \theta \\
& P_{s}=S_{X} \sin ^{2} \theta+S_{Y} \cos ^{2} \theta-S_{X Y} \sin 2 \theta
\end{aligned}
$$

relate the fracture reopening pressure $P_{r}$ and shut-in pressure $P_{s}$ to six components of the in situ stress field, which through Eqs. (1)-(3) may also be expressed in azimuth coordinates. In Eq. (4), relating $P_{r}$ to 
the in-situ stress components, the elastic theory accounts for stress concentrations at the borehole wall. In Eq. (5), $P_{s}$ is assumed to be equal to the stress normal across the fracture, which in turn can be related to the in situ stress components through simple stress projection on the fracture plane.

When the hydraulic fracture is inclined to the borehole axis (Fig. 1b), the $P_{s}$ relation to stress components can be defined by one governing equation, according to

$$
\begin{aligned}
P_{s}= & S_{N} \cos ^{2} \psi \cos ^{2} \varphi+S_{E} \sin ^{2} \psi \cos ^{2} \varphi+S_{V} \sin ^{2} \varphi \\
& +S_{N E} \sin 2 \psi \cos ^{2} \varphi+S_{E V} \sin \psi \sin 2 \varphi+S_{V N} \cos \psi \sin 2 \varphi
\end{aligned}
$$

again considering stress projection onto the fracture plane [17, 23]. In Eq. (6), $\varphi$ is the inclination of the normal to the fracture plane from the horizontal, and $\psi$ is the bearing of the normal to the fracture plane from the $\mathrm{N}$-axis. The derivation of governing equations above is described in detail as the matrix form of stress tensor in Appendix A.

In the HTPF, the orientation of the pressurized pre-existing fracture may not be directly related to the current stress field, because the fracture might have been created during past tectonic stressing. The stress acting normal across the fracture plane is commonly denoted $P_{n}$, the normal pressure acting on the fracture plane. $P_{n}$ may be determined by analyzing the pressure-flow rate record from a stepwise flow rate test. $P_{n}$ is related to the field stress state $S(X)$ at any point $X$ as

$$
P_{n}=S(X)(n \cdot n)
$$

where $n$ is the normal to the fracture plane $[2,6,19,20]$. In general, $P_{n}$ is interpreted to be equivalent to the shut-in pressure $P_{s}$, in that both are assumed to be equal to the normal pressure acting on the fracture plane. Eq. (7) can also be expressed explicitly with stress components in azimuth coordinates according to Eqs. (5) or (6), showing that $P_{n}$ corresponds to $P_{s}$.

\subsection{Integrated 3-D stress determination method}

For the 3-D stress analysis, the generalized relationships between in situ stresses are expressed as follows $[2,6,19,20]$ :

$$
\begin{aligned}
& \sigma\left(X^{m}\right)\left(n^{m} n^{m}\right)=P_{n}^{m} \\
& \operatorname{div}\left[\sigma\left(X^{m}\right)\right]-\rho\left(X^{m}\right) b_{i}=0
\end{aligned}
$$

where $\sigma\left(X^{m}\right)$ is the local stress tensor at point $X^{m}$ of the $m$ th test point, $n^{m}$ is the normal to the $m$ th fracture plane, $P_{n}{ }^{m}$ is the fracture normal pressure measured from field tests, $\rho\left(X^{m}\right)$ is the rock density at point $X^{m}$ and $b_{i}$ is the gravitational acceleration $\left(b_{i}=g \delta_{i 3} ; \delta_{i 3}=0\right.$ for $i \neq 3 ; \delta_{i 3}=1$ for $i=3$ ).

The rock mass volume subjected to stress measurements is discretized into subvolumes, within which the stress field is approximated by its first-order linear expansion. The local stress at the point $X^{m}$ of the $m$ th test point is given by 


$$
\sigma\left(X^{m}\right)=\sigma\left(X^{0}\right)+\left(x^{m}-x^{0}\right) \alpha^{[x]}+\left(y^{m}-y^{0}\right) \alpha^{[y]}+\left(z^{m}-z^{0}\right) \alpha^{[z]}
$$

where $\sigma\left(X^{0}\right)$ is the local stress tensor at the reference point $X^{0}, z^{m}$ is the depth of the $m$ th test point $X^{m}, z^{0}$ is the depth of the reference point, and $\alpha^{[x]}, \alpha^{[y]}$ and $\alpha^{[z]}$ are the second-order symmetrical tensors of the stress gradient in the $\mathrm{x}$-, $\mathrm{y}$ - and $z$-directions, respectively.

This first-order approximation of the stress field requires twenty-two parameters to be determined. For practical applications, the number of unknown parameters can be reduced using justifiable assumptions. In this work, the following assumptions are adopted, considering the depth and volume of rock mass subjected to field testing. These assumptions mean that the test region is considered as the homogeneous horizontal stress state with variation of the vertical stress induced by density and depth.

First, the test sections of all boreholes are located distant from the working drift to ignore the effect of the working drift (more than five times of the working drift radius) as shown in Fig. 2.

Second, the lateral stress variations are neglected because the region of the test is located at a depth of about $100 \mathrm{~m}$, which implies no topographical effect. The horizontal distance between the three boreholes is sufficiently small (less than $50 \mathrm{~m}$ ), which implies the homogeneous stress state region.

Third, the variation of principal stress direction with depth is neglected, because the depth ranges of all test boreholes are sufficiently small (less than $70 \mathrm{~m}$ in length as shown in Fig. 2).

Fourth, he stress varies linearly with depth, assuming homogeneity in the rock mass and negligible topographical effect.

Using these assumptions, the number of unknown parameters is reduced to ten, six stress components and four stress gradients with depth, where two parameters of the vertical stress component and the vertical stress gradient are constrained to the unit weight of rock layers above the test depth. Accordingly, Eq. (10) is simply expressed as

$$
\sigma\left(X^{m}\right)=\sigma\left(X^{0}\right)+\left(z^{m}-z^{0}\right) \alpha^{[z]}
$$

In the stress inversion analysis, the misfit function defines the discrepancy between observed and calculated values of the fracture normal pressure or shut-in pressure for all test points. The 3-D stress solution is determined from the stress component model, resulting in the minimum misfit function, $M F$, expressed as

$$
M F=\sqrt{\frac{\sum_{1}^{n}\left(P_{n, \text { cal }}-P_{n, \text { mea }}\right)^{2}}{n-1}}
$$

where $P_{n, \text { cal }}$ is the calculated value, $P_{n, \text { mea }}$ is the measured value, and $n$ is the total number of measurements [13-17]. The integrated 3-D stress determination method developed in this study employs a nonlinear least-squares optimization routine, using a modified Levenberg-Marquardt method and a finite- 
difference Jacobian algorithm for solving multivariable nonlinear equations [33].

\section{Field tests using multiple inclined boreholes}

The hydraulic fracturing stress measurements in our study were conducted at an underground cavern site, at Jurong Island, Singapore. The geological formations in this region belong to late Triassic to early Jurassic periods [35-37]. According to the site geotechnical data report [38], rock layers are classified in sequence from the ground surface as residual soil, weathered rock, a low confined zone, and fresh bedrock, with the rock type for the fresh bedrock being sandstone with some bedding features. Three boreholes for hydraulic fracturing tests were drilled from the floor of the cavern (Fig. 2). For the generalized 3-D stress determination, we designed the orientations of each of the three boreholes to be different. $\mathrm{BH}-1$ has a $133^{\circ}$ bearing clockwise from north, and $70^{\circ}$ of inclination; $\mathrm{BH}-2$ has a $348^{\circ}$ bearing clockwise from north, and $80^{\circ}$ of inclination; and BH-3 is vertical. The drilled lengths of the boreholes are $74 \mathrm{~m}$ (BH-1), $64 \mathrm{~m}$ (BH-2), and $60 \mathrm{~m}$ (BH-3), respectively. The thickness of the overburden above the borehole heads is $98 \mathrm{~m}$; therefore, the actual drilled depths are $172 \mathrm{~m}(\mathrm{BH}-1), 162 \mathrm{~m}(\mathrm{BH}-2)$ and $158 \mathrm{~m}$ (BH-3), respectively.

We use the wireline type hydraulic fracturing system as shown in Fig. 3. The straddle packer for fracturing consists of two inflatable rubber elements with $1.0 \mathrm{~m}$ length and the test interval with $0.8 \mathrm{~m}$ length. There are two hydraulic lines attached to the packers, one for the inflation of the packers and the other for the pressurization of the interval. Pressure transducer was placed in a sealed housing on the top of the straddle packer for measuring downhole pressure in the test interval. We developed a downhole pressure relief valve that facilitates the deflation of packer elements. The relief valve consists of a ball and a spring acting against the ball. In stage of packer inflation, fluid is partially blocked by the small venting holes drilled in ball-housing. In stage of packer deflation after the test, the spring pushes the ball to its normally open position and the pressure is released to a level equal to the water head. The straddle packer tool is lowered into the test hole using a depth-counted wireline winch. A notebook PC provides real-time plotting and digital recording of packer pressure, downhole interval pressure, surface interval pressure and flowrate.

According to the site geotechnical data report [38] and core logging from the test boreholes, bedding planes and scattered pre-existing fractures are present. Both HF and HTPF were carried out for all test points to ensure reliable data acquisition and to carry out the integrated stress analysis. Pressure-time records, sampled at a rate of 10 data points per second, were obtained from HF cyclic tests (fracturing-reopening-shut-in). Pressure and flow rate records were obtained from stepwise flow-rate tests in HTPF. Fracture traces on the borehole wall were investigated using an acoustic borehole 
televiewer (BHTV) as shown in Fig. 4. The sonde of BHTV has a high resolution of 1440 x 720 pixels. Scanning of the borehole wall was conducted twice before and after the test to determine whether new fractures were induced or whether pre-existing ones were re-opened. In case that it is not easy to determine whether the fracture image by BHTV is pre-existing one or not, we compared it with core logging data and also checked the occurrence of the peak breakdown point in the 1st injection stage of the pressure-time record.

\section{Analysis of fracture patterns and pressure parameters}

\subsection{Investigation of fracture traces}

Figure 5 shows BHTV images of typical newly induced fractures and two types of pre-existing fractures, with each fracture trace indicated within a red circle. Orientations of fractures for all test points are plotted in Fig. 6. The orientation data in Fig. 6 are calculated with reference to the true north. Most of the fracture traces indicate steeply inclined or subvertical fractures, and are more or less widely distributed in the dip direction. This tendency prevails in both pre-existing and induced fractures. The orientations of the three boreholes are different, leading to different stress conditions at borehole walls and, as a result, different fracture trace patterns may be induced. It also appears that the induced fracturing is somewhat affected by anisotropy and the bedding features of the host rock. As shown in Figs. 5 and 6, pre-existing fractures are dominant at the test region and affect the interpretation of pressure parameters in pressure-time records, as discussed in the following section.

\subsection{Determination of pressure parameters}

Figure 7 presents a typical pressure-versus-time record obtained from HF, and a pressure-and-flowrate versus-time record obtained from HTPF. The pressure parameters necessary for stress analysis by hydraulic fracturing are fracture reopening pressure $P_{r}$, fracture shut-in pressure $P_{s}$, and/or fracture normal pressure $P_{n}$. In this study, we determined $P_{r}$ using the bilinear pressure-versus-accumulatedinjection-volume $(P-V)$ method, and $P_{s}$ using the bilinear pressure-decay-rate method, from the pressureversus-time record. We also determined $P_{n}$ using the pressure-versus-flow-rate $(P-Q)$ method, from pressure-and-flow-rate-versus-time records [2, 25-27]. A typical result of the determination of these pressure parameters using actual test data is represented in Fig. 8.

These pressure parameters determined for all tests are plotted in Fig. 9 and summarized in Table 1, with the corresponding fracture patterns (IF: newly induced fracture, PF: pre-existing fracture). As shown in Fig. 9, the magnitudes of shut-in pressure and fracture normal pressure show a reliable consistency with depth. On the other hand, reopening pressures show a wide range in magnitudes with depth, with 
some reopening pressures for pre-existing fractures showing a similar level to shut-in or fracture normal pressures. This is related to the type of pre-existing fracture, especially those having an open fracture tip near the borehole wall.

Analytical or numerical studies on the uncertainty in determining pressure parameters related to fracture patterns have been reported in the literature [12, 13, 30-32]. For a 2-D open fracture model in which the injection fluid pressure acts not only on the borehole wall but also within the fracture, the variation in reopening pressure with fracture length is theoretically derived as shown in Fig. 10 [32]. In Fig. 10, $F$ is the ratio of reopening pressure to fracture normal (or shut-in) pressure, where $a$ is the radius of a borehole and $r$ is the distance from borehole center to the open fracture tip. When the fracture is closed at the borehole wall under the unpressurized condition, it becomes $F=0.5(3-K)$ by substituting $r=a$ where $K$ is stress ratio $\left(K=S_{H} / S_{h}\right)$. The detailed analysis for a pre-existing fracture model is described in Appendix B.

Figure 10 shows that reopening pressure is very sensitive to the length of the open fracture tip and varies considerably when the open fracture tip is near the borehole wall. This relationship between fracture pattern and reopening pressure reveals that the governing equation for an open-tip-fracture model, rather than the conventional governing equation for a closed fracture model, is necessary for properly determining the reopening pressure. Based on this analysis, the wide distribution of reopening pressures (Fig. 9a) is explained by the existence of various kinds of open pre-existing fractures at all test points (as typically shown in Fig. 5). Therefore, it is inadequate to relate the values of these reopening pressures to the governing equations adopted in this stress inversion analysis, which assumes closed fractures, whether induced or pre-existing.

\subsection{Interpretation and screening of input data for stress analysis}

For accuracy and reliability in our stress inversion analysis, various techniques were used to select a proper data set (pressure parameters and corresponding fracture traces) as initial input, as well as to exclude uncertain data points.

First, according to the aforementioned analysis of fracture patterns and pressure parameters (Figs. 5, 9 and 10), reopening pressures for open, pre-existing fractures are inadequate for the governing equation in this analysis. We also found that applying the governing equation based on isotropic elasticity may be inadequate for calculating the reopening pressure, considering that fracture and stress concentration features around the borehole could be influenced by the local anisotropy and stratigraphy in the host rock. Therefore, even in the HF, Eq. (4) related to fracture reopening pressure was excluded, and Eq. (5) or Eq. (6), based on the relationship between fracture plane and fracture shut-in pressure (or fracture normal pressure), was adopted. 
Second, by comparing the fracture trace geometry with the pressure-time record, including the difference between the peak pressure values of the 1st pressurizing cycle and the following reopening cycles, we could determine whether a new or pre-existing fracture is activated during pressurization.

Third, two values of fracture shut-in pressure and fracture normal pressure measured by HF and HTPF respectively were validated by comparison with the fracture pattern. As a result, the most reliable data set (pressure parameter and corresponding fracture geometry) could be selected: basically, shut-in pressure for induced fractures and fracture normal pressure for pre-existing fractures.

Fourth, in the process of stress analysis, the reliability of the data set was checked by analyzing the misfit between the measured and the inverted stress. A particular data point was excluded in the final stress calculation when its misfit was beyond the confidence range.

\section{Estimation of 3-D stress state}

The vertical stress component is calculated as the sum of the overburden weights of layers above the depth of interest [2].

$$
S_{V}=\sum_{i=1}^{n} \rho_{i} g Z_{i}
$$

where $\rho_{i}$ is the mean mass density of rock layer $i, g$ is the local gravitational acceleration, $Z_{i}$ is the thickness of layer $i$, and $n$ is the number of rock layers overlying the test zone. Using the classification of rock layers (Fig. 2) and the density of layers based on the site geotechnical data report [38], the vertical stress was calculated according to

$$
S_{V}[\mathrm{MPa}]=2.04[\mathrm{MPa} / \mathrm{m}]+0.028[\mathrm{MPa} / \mathrm{m}] \times(Z[\mathrm{~m}]-85)
$$

where 85 signifies the total depth in meters from the ground surface to the upper boundary of fresh bedrock. Eq. (14) can be used to calculate the vertical stress at any depth below $Z=85 \mathrm{~m}$, which is within the fresh bedrock region.

The results of the 3-D stress state inversion are presented in Table 2. The stress in the northern direction $\left(S_{N}\right)$ is larger than the stress in the eastern direction $\left(S_{E}\right)$ over the entire depth range. Stress gradients of $S_{N}, S_{E}$ and $S_{V}$ with depth are inverted as $0.04 \mathrm{MPa} / \mathrm{m}, 0.045 \mathrm{MPa} / \mathrm{m}$, and $0.028 \mathrm{MPa} / \mathrm{m}$, respectively. The stress gradient of $S_{E}$ is slightly larger than that of $S_{N}$, whereas that of $S_{V}$ is constrained to the unit weight of the fresh bedrock.

We express depth trends for the 3-D stress field using correlation equations. The depth trends of magnitudes and ratios among the principal stresses are shown in Fig. 8. In the equations for three principal stresses in Fig. 11, we adopt an upper depth boundary of $100 \mathrm{~m}$, just above the measurement depth range of 120-160 m. This is reasonable, since we expect that the inverted stress field would also be 
valid within the fresh bedrock just above and below the measurement interval. The calculated ranges of magnitude for maximum, intermediate, and minimum principal stresses $\left(S_{1}, S_{2}, S_{3}\right)$ are 6.2-7.8 MPa, 4.26.1 MPa, and 2.9-3.9 MPa, respectively (Fig. 11a), and with orientations (bearing/inclination) of N26 ${ }^{\circ} \mathrm{E} /-$ $5^{\circ}, \mathrm{S} 62^{\circ} \mathrm{E} /-17^{\circ}$, and $\mathrm{S} 81^{\circ} \mathrm{E} / 71^{\circ}$, respectively. The ratio of maximum to minimum, maximum to intermediate, and intermediate to minimum principal stress is $1.98-2.16,1.27-1.47$ and $1.47-1.56$, respectively, and gradually decreases with depth (Fig. 11b). Overall, the maximum principal stress is subhorizontal and directed approximately NNE-SSW, whereas the minimum principal stress is almost vertical. The ratios between the principal stresses are $S_{1} / S_{3}=2.0-2.3$ and $S_{2} / S_{3}=1.4-1.5$, whereas the ratios of horizontal to vertical stresses are calculated as $S_{H} / S_{V}=1.9-2.2$ and $S_{h} / S_{V}=1.3-1.4$. This is reasonable, since at these shallow depths, the minimum principal stress is frequently vertical [39].

\section{Scatter analysis of the integrated inversion result and comparison with field measurements}

To evaluate the reliability of the integrated 3-D stress inversion result obtained by combining the data from all three boreholes, we analyzed the scatter between the result of the integrated stress inversion and the field measurement data for each borehole. Scatter is defined as a gap in pressure, shut-in pressure $P_{s}$ or fracture normal pressure $P_{n}$, between the inversion and the measurement at each test point. Here, it is expressed, with the relative percentage ratio, as

$$
S C R=\frac{P_{n, \text { cal }}-P_{n, \text { mea }}}{P_{n, \text { cal }}} \times 100(\%)
$$

Figure 12 shows that the scatter expressed as percentage ratio of pressure gap, $S C R$, is $8.2 \%$ on average, with a standard deviation of $5.2 \%$ for all data sets from the three boreholes, whereas it is 7.7$8.5 \%$ on average, with a standard deviation of $3.7-6.6 \%$ for data sets from each borehole. The scatters for all cases are less than $10 \%$ on average. The difference in average and standard deviation among each borehole is $0.1-0.8 \%$ and $0.1-3.0 \%$ respectively, whereas that for each borehole and for combining all boreholes is $0.2-0.5 \%$ and $1.4-2.6 \%$, respectively. This shows that there is no significant deviation between the measurements of each borehole and the overall trend of integrated 3-D stress inversion results. While they all are drilled in different directions, the three boreholes are located within $50 \mathrm{~m}$ from 
each other and within the same rock unit (Fig. 2). As a result, it is reasonable to carry out the stress inversion analysis by combining all three boreholes under the same stress field conditions.

\section{Stress analysis per individual borehole}

We compared the result of the integrated 3-D stress inversion combining all data sets from all three boreholes with that for data sets from each individual borehole. The volume of data for each individual borehole was not sufficient, however, to derive a generalized 3-D stress field equivalent to the case of combining all three boreholes. Therefore, we constrained the stress gradient coefficient with depth, assuming it to be constant, thereby reducing the number of unknown variables in the 3-D stress inversion analysis per each individual borehole. The inversion per each individual borehole resulted in a difference of $12-20 \%$ in magnitude and $2-33^{\circ}$ in direction (bearing), compared to that for combining all boreholes (Fig. 13), while the overall trends, including this difference, still show an orientation in the N-NNE direction of maximum principal stress.

The factors causing this difference include the volume of data and the constraint of unknown stress variables. The volume of data and their effect are taken into consideration by the statistical confidence analysis of the result per individual borehole. Defining the scatter interval (or confidence interval) as $S I=(S D \times R F) / S Q R T$ (volume_of_data) in statistics, where $S D$ is the standard deviation and $R F$ is the reliability factor given by the confidence level, we find that the scatter interval is inversely proportional to the volume of data. The scatter interval calculated for each individual borehole increases by about 1.5 to 2 times when the volume of data decreases by half (12 for BH-2) to one-third (7 or 5 for $\mathrm{BH}-1$ or $\mathrm{BH}-3$ ) respectively, compared to that for combining three boreholes ( 24 for all). In other words, the wider the scatter interval, the larger the deviation in the result.

Within the stress inversion, constraints imposed on unknown stress parameters as well as the volume of data may result in a residual misfit beyond the convergence tolerance. According to the inversion results per each individual borehole (assuming stress gradient with depth, one of the unknown stress

parameters, to be constant), the shear stress component (especially acting in the $N-E$ plane, in this case) is more affected than other stress components, showing a non-negligible difference in its magnitude among three boreholes.

As shown in Fig. 13, this difference results in some deviation in the direction (bearing) of the maximum principal stress among the three boreholes. We also guess that the anisotropy and the bedding features of this test region might affect this difference, especially the difference of orientation of stresses, while anisotropy factor analysis in 3-D HF stress analysis is another matter beyond the theme of this study. 


\section{Summary and conclusion}

We have carried out a complete three-dimensional stress determination, using hydraulic fracturing data from three inclined boreholes drilled from the floor of an underground cavern at a depth of about 100 $\mathrm{m}$. The analysis was based on stress measurements using both conventional hydraulic fracturing (HF) and hydraulic testing of pre-existing fractures (HTPF) on a number of tests along each of the three boreholes.

Fracture traces on the borehole wall of each test point were investigated before and after the test, using an acoustic borehole televiewer. The acoustic images showed that the directions of fractures for all test points were quite widely distributed for both pre-existing and newly induced fractures. This wide distribution was attributed to both differences in borehole geometry and anisotropy associated with bedding features in the host rock.

Our 3-D stress determination was conducted using a numeric inversion code that integrates the entire data set from HF and HTPF, and that includes a nonlinear least-squares optimization routine, based on a modified Levenberg-Marquardt method and a finite-difference Jacobian algorithm for solving multivariable nonlinear equations. We found that applying the equations for reopening pressure based on elasticity may not be adequate, considering the features of open, pre-existing fractures and the stress concentration around the borehole being influenced by the observed anisotropy and stratigraphy in the host rock. Instead, two values of fracture shut-in pressure and fracture normal pressure measured by HF and HTPF were compared with the fracture pattern, resulting in more reliable pressure parameters as input to the numerical inversion of the 3D stress field.

Complete 3-D stress states were finally determined, and stress variations with depth were expressed with correlation equations including the scatter analysis. The trend of inverted stress state showed that the maximum principal stress is subhorizontal and directed approximately NNE-SSW, whereas the minimum principal stress is almost vertical. The stress ratios among three principal stresses were calculated as $S_{1} / S_{3}$ $=2.0$ and $S_{2} / S_{3}=1.5$ on average, over a test depth range of $100-160 \mathrm{~m}$.

According to scatter analysis of the results for the integrated stress inversion and the comparison with field measurement data for each borehole, the scatters for all cases are less than $10 \%$ on average. The three boreholes are located within $50 \mathrm{~m}$ from each other; consequently, it is reasonable to conduct the 3-D stress inversion analysis by combining all three boreholes under consideration within the same stress field condition.

Finally, we compared the 3-D stress state determined for combining all three boreholes with that determined independently for each individual borehole. The 3-D stress inversion per individual borehole required constraining an unknown stress variable, because of the limited volume of data. While the 
constraint condition for individual boreholes caused some differences in the inversion results compared to that of combining all boreholes, the results were generally consistent with the maximum principal stress in the N-NNE direction and with the trend of the magnitude variation with depth.

\section{Acknowledgments}

This research was supported by the Basic Research Project of the Korea Institute of Geoscience and Mineral Resources (KIGAM, GP2012-001) funded from the Ministry of Science, ICT and Future Planning of Korea and the project of Korea Institute of Geoscience and Mineral Resources (KIGAM, IP2010-024) commissioned by Heesong Geotek Co., funded from Hyundai Engineering \& Construction Co., LTD, Korea. The authors wish to acknowledge the support of the JTC Corporation, Singapore, on the test site and field work. Funding from KIGAM for Jonny Rutqvist was provided through the U.S. Department of Energy Contract No. DE-AC02-05CH11231. Editorial review by Dan Hawkes at Lawrence Berkeley National Laboratory is greatly appreciated.

\section{Appendix A. Governing equations for 3-D HF stress analysis}

We consider three coordinate systems for a longitudinal fracture as shown in Fig. 1(a). The $N-E-V$ coordinate represents the azimuth of north, east, and vertical direction. The $X-Y-Z$ coordinate is related to borehole geometry where $X-Y$ is on the plane of a borehole section and $Z$ is the direction of a borehole axis. The $x-y-z$ coordinate is related to a fracture geometry where $x-y$ is on the fracture plane and $z$ is the same direction as $Z$. And $\alpha$ is the bearing of the borehole from the $N$-axis, $\beta$ is the inclination of the borehole from the $V$-axis, and $\theta$ is the direction of the fracture from the $X$-axis.

We derive the relationship between the stress components $\left(S_{X}, S_{Y}, S_{X Y}\right)$ in the $X-Y-Z$ coordinate of a borehole geometry and the stress components $\left(S_{N}, S_{E}, S_{V}, S_{N E}, S_{E V}, S_{V N}\right)$ in the $N-E-V$ coordinate using stress diagram for rotation of coordinate axes[17, 34].

$$
\left[\begin{array}{c}
S_{X} \\
S_{Y} \\
S_{X Y}
\end{array}\right]=\left[\begin{array}{cccccc}
\cos ^{2} \alpha \cos ^{2} \beta & \sin ^{2} \alpha \cos ^{2} \beta & \sin ^{2} \beta & \sin 2 \alpha \cos ^{2} \beta & \sin \alpha \sin 2 \beta & \cos \alpha \sin 2 \beta \\
\sin ^{2} \alpha & \cos ^{2} \alpha & 0 & -\sin 2 \alpha & 0 & 0 \\
-0.5 \sin 2 \alpha \cos \beta & 0.5 \sin 2 \alpha \cos \beta & 0 & \cos 2 \alpha \cos \beta & -\cos \alpha \sin \beta & \sin \alpha \sin \beta
\end{array}\right]\left[\begin{array}{l}
S_{N} \\
S_{E} \\
S_{V} \\
S_{N E} \\
S_{E V} \\
S_{V N}
\end{array}\right]
$$

We also derive the relationship between the stress components $\left(S_{x}, S_{y}, S_{x y}\right)$ in the $x-y-z$ coordinate of a fracture geometry and the stress components $\left(S_{X}, S_{Y}, S_{X Y}\right)$ in the $X-Y-Z$ coordinate. 
$\left[\begin{array}{l}S_{x} \\ S_{y} \\ S_{x y}\end{array}\right]=\left[\begin{array}{ccc}\cos ^{2} \theta & \sin ^{2} \theta & -\sin 2 \theta \\ \sin ^{2} \theta & \cos ^{2} \theta & -\sin 2 \theta \\ -0.5 \sin 2 \theta & 0.5 \sin 2 \theta & \cos 2 \theta\end{array}\right]\left[\begin{array}{c}S_{X} \\ S_{Y} \\ S_{X Y}\end{array}\right]$

According to the theory of hydraulic fracturing on a borehole wall, the fracture reopening pressure $P_{r}$ and the fracture shut-in pressure $P_{s}$ are related with the stress components $\left(S_{x}, S_{y}, S_{x y}\right)$ in the $x-y-z$ coordinate of a fracture geometry.

$\left[\begin{array}{l}P_{r} \\ p_{s}\end{array}\right]=\left[\begin{array}{cc}-1 & 3 \\ 0 & 1\end{array}\right]\left[\begin{array}{l}S_{x} \\ S_{y}\end{array}\right]$

By adopting Eq. (A.2) into Eq. (A.3), we obtain the governing equation for a longitudinal fracture as Eq. (A.4) which is a matrix form of Eq. (4) and (5). We can also express Eq. (A.4) in terms of the stress components $\left(S_{N}, S_{E}, S_{V}, S_{N E}, S_{E V}, S_{V N}\right)$ in the $N-E-V$ coordinate by adopting Eq. (A.1) into Eq. (A.4).

$\left[\begin{array}{c}P_{r} \\ P_{s}\end{array}\right]=\left[\begin{array}{ccc}\left(3 \sin ^{2} \theta-\cos ^{2} \theta\right) & -\left(3 \cos ^{2} \theta-\sin ^{2} \theta\right) & -4 \sin 2 \theta \\ \sin ^{2} \theta & \cos ^{2} \theta & -\sin 2 \theta\end{array}\right]\left[\begin{array}{c}S_{X} \\ S_{Y} \\ S_{X Y}\end{array}\right]$

We consider the case of a transverse fracture as shown in Fig. 1(b). The $y$ axis is the direction normal to the fracture plane, where $\varphi$ is the inclination of the normal to the fracture plane from the horizontal and $\psi$ is the bearing of the normal to the fracture plane from the $\mathrm{N}$-axis. We also derive the relationship between the stress component $\left(S_{y}\right)$ in the $x-y-z$ coordinate of a fracture geometry and the stress components $\left(S_{N}, S_{E}, S_{V}, S_{N E}, S_{E V}, S_{V N}\right)$ in the $N-E-V$ coordinate using stress diagram for rotation of coordinate axes $[17,34]$. The direction of $S_{y}$ is normal to the fracture plane and it corresponds to the fracture shut-in pressure $P_{s}$.

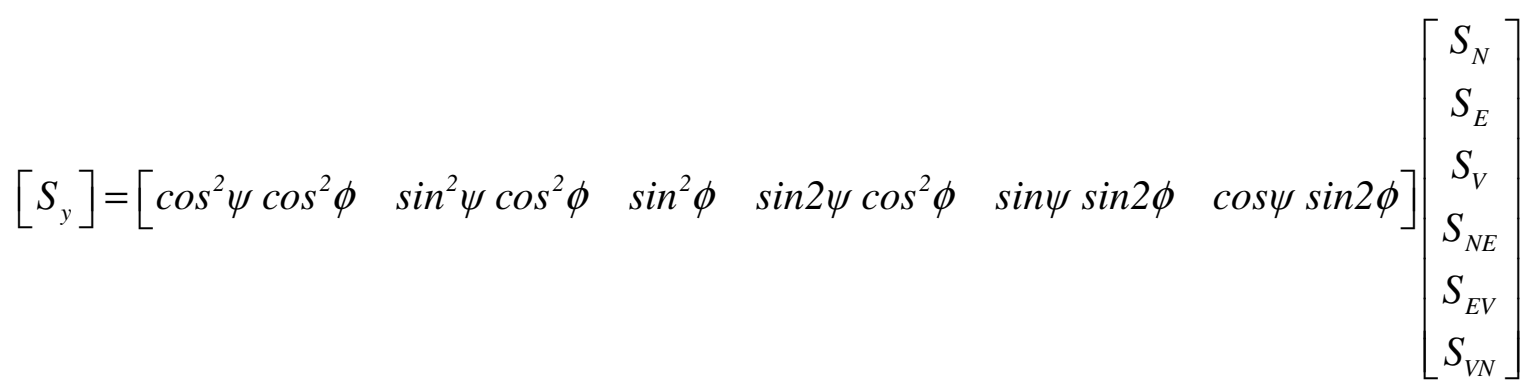

$P_{s}=S_{y}$

By adopting Eq. (A.5) into Eq. (A.6), we obtain the governing equation for a transverse fracture with a matrix form of Eq. (6). 


\section{Appendix B. Reopening pressure analysis in a pre-existing fracture model}

We derive the fracture reopening pressure equation, $F$, which is represented in Fig. 7. Considering a pre-existing fracture model (Fig. B.1), the tangential stress functions, $\sigma_{\theta}$, at borehole wall induced by insitu stresses and injected fluid pressure are represented as

$$
\begin{aligned}
& \sigma_{\theta}\left(S_{H}, S_{h}\right)=\frac{3}{2}\left(S_{h}-S_{H}\right) \frac{a^{4}}{r^{4}}+\frac{1}{2}\left(S_{h}+S_{H}\right) \frac{a^{2}}{r^{2}}+S_{h} \\
& \sigma_{\theta}\left(P_{w}\right)=-P_{w} \frac{a^{2}}{r^{2}} \\
& \sigma_{\theta}\left(P_{f}\right)=-P_{w}
\end{aligned}
$$

where $S_{H}$ is the maximum in-situ stress, $S_{h}$ is the minimum in-situ stress, $P_{w}$ is the injected fluid pressure in a borehole, $P_{f}$ is the pressure acting on a fracture plane by $P_{w}, a$ is the borehole radius and $r$ is the distance from the center of a borehole.

We consider, for the slightly open fracture model, that the injected fluid pressure $P_{w}$ acts on not only the borehole wall but also the fracture tip which is open. The total tangential stress is expressed as

$$
\sigma_{\theta}=\sigma_{\theta}\left(S_{H}, S_{h}\right)+\sigma_{\theta}\left(P_{w}\right)+\sigma_{\theta}\left(P_{f}\right)=\frac{3}{2}\left(S_{h}-S_{H}\right) \frac{a^{4}}{r^{4}}+\frac{1}{2}\left(S_{h}+S_{H}\right) \frac{a^{2}}{r^{2}}+S_{h}-P_{w}\left(\frac{a^{2}}{r^{2}}+1\right)
$$

The fracture reopens when the injected fluid pressure $P_{w}$ reaches the fracture reopening pressure $P_{r}$, which means that $\sigma_{\theta}$ equals to zero. By replacing $P_{w}$ with $P_{r}$ in Eq. (B.4),

$$
\sigma_{\theta}=0 \rightarrow \frac{3}{2}\left(S_{h}-S_{H}\right) \frac{a^{4}}{r^{4}}+\frac{1}{2}\left(S_{h}+S_{H}\right) \frac{a^{2}}{r^{2}}+S_{h}-P_{r}\left(\frac{a^{2}}{r^{2}}+1\right)=0
$$

Dividing Eq. (B.5) by $S_{h}$ and introducing the stress ratio $K=S_{H} / S_{h}$ and the reopening pressure factor $F=P_{r} / S_{h}$, Eq. (B.5) is expressed as

$$
\begin{aligned}
& \frac{3}{2}(1-K) \frac{a^{4}}{r^{4}}+\frac{1}{2}(1+K) \frac{a^{2}}{r^{2}}+1-F\left(\frac{a^{2}}{r^{2}}+1\right)=0 \\
& F=\frac{P_{r}}{S_{h}}=\left[\frac{3}{2}(1-K) \frac{a^{4}}{r^{4}}+\frac{1}{2}(1+K) \frac{a^{2}}{r^{2}}+1\right] /\left(\frac{a^{2}}{r^{2}}+1\right)
\end{aligned}
$$

When the fracture tip is open just at the borehole wall with $r=a$, Eq. (B.6) simply becomes 
$F=0.5(3-K)$ or $S_{H}=3 S_{h}-2 P_{r}$

Equation (B.7) corresponds to the well-known equation of the maximum in-situ stress calculation for the case of slightly open fracture at the borebole wall[12, 13]. Eq. (B.6) shows that fracture reopening pressure is very sensituve to the length of the open fracture tip when it is small at near the borehole wall, as shown in Fig. 7.

\section{References}

[1] Ljunggren C, Chang Yanting, Janson T, Christiansson R. An overview of rock stress measurement methods. Int J Rock Mech Min Sci 2003; 40:975-89.

[2] Haimson BC, Cornet FH. ISRM suggested methods for rock stress estimation - Part 3: hydraulic fracturing(HF) and/or hydraulic testing of pre-existing fractures(HTPF). Int J Rock Mech Min Sci 2003; 40:1011-20.

[3] Stephansson O, Zang A. ISRM suggested methods for rock stress estimation - Part 5: establishing a model for the in situ stress at a given site. Rock Mech Rock Eng 2012; 45:955-69.

[4] Cornet FH, Valette B. In situ stress determination from hydraulic injection test data. J Geophys Res 1984; 89(B13):11527-37.

[5] Cornet FH. Stress determination from hydraulic tests on preexisting fractures - the HTPF method. In: O Stephansson (ed), Rock Stress and Rock Stress Measurements, Centek Publishers, Lulea, Sweden, 1986, p. 301-12.

[6] Cornet FH. The HTPF and the integrated stress determination methods. In: Hudson JA, editor. Comprehensive Rock Engineering. Oxford: Pergamon Press; 1993, p. 413-32.

[7] Hubbert MK, Willis DG. Mechanics of hydraulic fracturing. Trans AIME 1957; 210:153-63.

[8] Schmitt DR, Zoback MD. Poroelastic effects in the determination of the maximum horizontal principal stress in hydraulic fracturing tests - a proposed breakdown equation employing a modified effective stress relation for tensile failure. Int J Rock Mech Min Sci Geomech Abstr 1989; 26(6):499506.

[9] Ito T. Effect of pore pressure gradient on fracture initiation in fluid saturated porous media. Eng Fract Mech 2008; 75:1753-62.

[10] Schmitt DR, Zoback MD. Infiltration effects in the tensile rupture of thin walled cylinders of glass and granite: Implications for the hydraulic fracturing breakdown equation. Int J Rock Mech Min Sci Geomech Abstr 1993; 30(3):289-303.

[11] Hayashi K, Sato A, Ito T. In situ stress measurement by hydraulic fracturing for a rock mass with many planes of weakness. Int J Rock Mech Min Sci Geomech Abstr 1997; 34(1):45-58. 
[12] Rutqvist J, Stephansson O. A cyclic hydraulic jacking test to determine the in situ stress normal to a fracture. Int J Rock Mech Min Sci Geomech Abstr 1996; 33(7):695-711.

[13] Rutqvist J, Tsang Chin-Fu, Stephansson O. Uncertainty in the maximum principal stress estimated from hydraulic fracturing measurements due to the presence of the induced fracture. Int $\mathbf{J}$ Rock Mech Min Sci 2000; 37:107-20.

[14] Cornet FH, Li L, Hulin JP, Ippolito I, Kurowski P. The hydromechanical behavior of a fracture: an in situ experimental case study. Int J Rock Mech Min Sci 2003; 40:1257-70.

[15] Liu Z, Chen M, Zhang G. Analysis of the influence of a natural fracture network on hydraulic fracture propagation in carbonate formations. Rock Mech Rock Eng 2014; 47:575-87.

[16] Rummel F, Hansen J. Interpretation of hydrofrac pressure recordings using a simple fracture mechanics simulation model. In: Proceedings $2^{\text {nd }}$ Int Workshops on Hydraulic Fracturing Stress Measurements, 1988, p. 646-67.

[17] Kuriyagawa M, Kobayashi H, Matsunaga I, Yamaguchi T, Hibiya K. Application of hydraulic fracturing to three dimensional in-situ stress measurements. In: Proceedings $2^{\text {nd }}$ Int Workshops on Hydraulic Fracturing Stress Measurements, 1988, p. 307-40.

[18] Mizuta Y, Sano O, Ogino S, Katoh K. Three dimensional stress determination by hydraulic fracturing for underground excavation design. Int J Rock Mech Min Sci Geomech Abstr 1987; 24(1):15-29.

[19] Cornet FH, Wileveau Y, Bert B, Darcy J. Complete stress determination with the HTPF tool in a mountainous region. Int J Rock Mech Min Sci 1997; 34(3-4):57.e1-15.

[20] Ask D. New developments in the integrated stress determination method and their application to rock stress data at the Aspo HRL, Sweden. Int J Rock Mech Min Sci 2006; 43:107-26.

[21] Klee G, Rummel F. Forsmark site investigation: Rock stress measurements with hydraulic fracturing and hydraulic testing of pre-existing fractures in borehole KFM01A, KFM01B, KFM02A and KFM04A - Results of in-situ tests, Report No. P-04-311, 2004.

[22] Klee G, Rummel F. Hydraulic fracturing / hydraulic injection stress measurements in borehole V BH4-10, Final Report Part I: Results of in-situ tests, 2007.

[23] Synn JH. Model testing and numerical analysis for the evaluation of 3-dimensional stress state and fracture propagation characteristics by hydraulic fracturing, $\mathrm{PhD}$ thesis, Seoul National University, Korea, 1990.

[24] Warren WE, Smith CW. In situ stress estimates from hydraulic fracturing and direct observation of crack orientation. J Geophys Res 1985; 90(B8):6829-39.

[25] Haimson BC. The hydraulic fracturing method of stress measurement: theory and practice. In: Hudson JA, editor. Comprehensive Rock Engineering. Oxford: Pergamon Press; 1993, p. 395-412. 
[26] Haimson BC, Tunbridge LW, Lee MY, Cooling CM. Measurement of rock stress using the hydraulic fracturing method in Cornwall, U.K. - Part II. Data reduction and stress calculation. Int J Rock Mech Min Sci Geomech Abstr 1989; 26(5):361-72.

[27] Lee MY, Haimson BC. Statistical evaluation of hydraulic fracturing stress measurement parameters. Int J Rock Mech Min Sci Geomech Abstr 1989; 26(6):447-56.

[28] Ryu DW, Lee HK, Choi SO. Development of intergrated hydrofracturing data processing program by statistical approach. In: Proceedings of the Korea-Japan Joint Symposium on Rock Engineering, 1996, p. 225-30.

[29] Hardy MP, Asgian MI. Fracture reopening during hydraulic fracturing stress determinations. Int J Rock Mech Min Sci Geomech Abstr 1989; 26(6):489-97.

[30] Ito T, Evans K, Kawai K, Hayashi K. Hydraulic fracture reopening pressure and the estimation of maximum horizontal stress. Int J Rock Mech Min Sci 1999; 36:811-26.

[31] Nelson EJ, Chipperfield ST, Hillis RR, Gilbert J, McGowen J, Mildren SC. The relationship between closure pressures from fluid injection tests and the minimum principal stress in strong rocks. Int $\mathbf{J}$ Rock Mech Min Sci 2007; 44:787-801.

[32] Synn JH, Park C, Park CW, Kim KS. Stress parameter analysis in hydraulic fracturing with open fracture pattern. In: Proceedings $12^{\text {th }}$ ISRM International Congress on Rock Mechanics: Harmonising Rock Engineering and the Environment, China, 2011, p. 1131-6.

[33] Visual Numerics, Inc. IMSL Fortran Numerical Math Library, Version 6.0, p. 1217-418.

[34] Obert L, Duvall WI. Rock mechanics and the design of structures in rock. John Wiley \& Sons; 1967 , P. 18-25.

[35] Sharma JS, Chu J, Zhao J. Geological and geotechnical features of Singapore: an overview. Tunnelling and Underground Space Technology 1999; 14(4):419-31.

[36] Zhao J, Liu Q, Lee KW, Choa V, Teh CI. Underground cavern development in the Jurong sedimentary rock formation. Tunnell Undergr Space Tech 1999; 14(4):449-59.

[37] Zhao J, Hefny AM, Zhou YX. Hydrofracturing in situ stress measurements in Singapore granite. Int J Rock Mech Min Sci 2005; 42(3-4):577-83.

[38] JTC Corporation. Phase 1 Jurong rock cavern at Banyan basin, Jurong island underground caverns, associated underground/aboveground facilities and Jetty basic engineering design and construction management services - Geotechnical data report, Report No. JRC-C04-G-13-GEN-30002, 2007.

[39] Zhang A, Stephansson O. Stress field of the earth's crust. Berlin: Springer; 2010, 342 p. 
Table 1. Summary of pressure parameters and fracture traces.

\begin{tabular}{|c|c|c|c|c|c|c|}
\hline $\begin{array}{l}\text { Borehole } \\
\text { no. }\end{array}$ & $\begin{array}{l}\text { Test } \\
\text { depth } \\
(\mathrm{m})\end{array}$ & $\begin{array}{l}\mathrm{P}_{\mathrm{r}} \text { from } \\
\mathrm{P}-\mathrm{T} \text { record } \\
(\mathrm{MPa})\end{array}$ & $\begin{array}{l}\mathrm{P}_{\mathrm{s}} \text { from } \\
\mathrm{P}-\mathrm{T} \text { record } \\
(\mathrm{MPa})\end{array}$ & $\begin{array}{l}\mathrm{P}_{\mathrm{n}} \text { from } \\
\mathrm{P}-\mathrm{Q} \text { record } \\
(\mathrm{MPa})\end{array}$ & $\begin{array}{l}\text { Dip dir. / Dip } \\
\text { of fracture } \\
\text { (deg.) }\end{array}$ & $\begin{array}{l}\text { Fracture pattern } \\
\text { (IF: induced frac, PF: pre-existing frac) }\end{array}$ \\
\hline \multirow[t]{7}{*}{ BH-1 } & 136.5 & 6.51 & 4.32 & 4.52 & $94 / 90$ & PF : sub-vertical \\
\hline & 139.0 & 9.28 & 5.82 & 5.92 & $264 / 89$ & PF : sub-vertical \\
\hline & 141.1 & 7.47 & 4.69 & 5.12 & $271 / 79$ & PF : steep-inclined \\
\hline & 149.5 & 8.01 & 6.95 & 6.65 & $188 / 62,71 / 88$ & IF : sub-vertical \& moderate inclined \\
\hline & 153.0 & 5.44 & 5.16 & 4.27 & $18 / 40$ & IF : moderate-inclined \\
\hline & 158.5 & 13.40 & 7.86 & - & $141 / 85,72 / 69$ & IF+PF : sub-vertical \& steep-inclined \\
\hline & 160.3 & 6.36 & 5.81 & 5.46 & $273 / 75$ & PF : steep-inclined \\
\hline \multirow[t]{8}{*}{$\mathrm{BH}-2$} & 121.0 & 5.23 & 4.01 & 4.71 & $287 / 83,269 / 87$ & IF : sub-vertical \& steep-inclined \\
\hline & 126.5 & 5.92 & 3.62 & 4.65 & $248 / 53$ & IF : moderate-inclined \\
\hline & 129.0 & 7.93 & 4.78 & 5.97 & $295 / 81,270 / 87$ & IF $:$ sub-vertical \\
\hline & 134.5 & 6.40 & 5.07 & 5.06 & $350 / 76$ & PF : steep-inclined \\
\hline & 140.0 & 5.12 & 3.75 & 4.33 & $196 / 33,188 / 16$ & PF : gentle-inclined \\
\hline & 144.0 & 6.34 & 5.49 & 6.47 & $344 / 86$ & PF : steep-inclined \\
\hline & 148.5 & 6.40 & 4.57 & 4.51 & $159 / 51$ & IF : moderate-inclined \\
\hline & 151.5 & 6.50 & 5.74 & 6.01 & $201 / 79$ & PF : steep-inclined \\
\hline \multirow[t]{4}{*}{ BH-3 } & 138.5 & 10.49 & 6.53 & - & $163 / 80$ & IF+PF : steep-inclined, complex \\
\hline & 143.5 & 9.87 & 7.25 & 7.34 & $351 / 82,58 / 82$ & IF : sub-vertical \\
\hline & 145.5 & 4.92 & 5.30 & 4.74 & $263 / 58$ & PF : moderate-inclined \\
\hline & 149.0 & 7.06 & 5.18 & 5.23 & $97 / 86$ & PF : sub-vertical, complex \\
\hline
\end{tabular}

Table 2. Results of integrated 3-D stress inversion for combining all boreholes.

\begin{tabular}{|c|c|c|c|c|c|c|c|c|c|c|}
\hline \multirow{2}{*}{$\begin{array}{l}\text { Borehole } \\
\text { no. }\end{array}$} & \multirow{2}{*}{$\begin{array}{l}\text { Test } \\
\text { depth } \\
\text { (m) }\end{array}$} & \multicolumn{6}{|c|}{ 3-D stress components in $N-E-V$ coordinate } & \multicolumn{3}{|c|}{ Principal stresses } \\
\hline & & $\begin{array}{l}\mathrm{S}_{\mathrm{N}} \\
(\mathrm{MPa})\end{array}$ & $\begin{array}{l}\mathrm{S}_{\mathrm{E}} \\
(\mathrm{MPa})\end{array}$ & $\begin{array}{l}\mathrm{S}_{\mathrm{V}} \\
(\mathrm{MPa})\end{array}$ & $\begin{array}{l}\mathrm{S}_{\mathrm{NE}} \\
(\mathrm{MPa})\end{array}$ & $\begin{array}{l}\mathrm{S}_{\mathrm{EV}} \\
(\mathrm{MPa})\end{array}$ & $\begin{array}{l}\mathrm{S}_{\mathrm{VN}} \\
(\mathrm{MPa})\end{array}$ & $\begin{array}{l}\mathrm{S}_{1} \\
(\mathrm{MPa})\end{array}$ & $\begin{array}{l}\mathrm{S}_{2} \\
(\mathrm{MPa})\end{array}$ & $\begin{array}{l}\mathrm{S}_{3} \\
(\mathrm{MPa})\end{array}$ \\
\hline \multirow[t]{6}{*}{$\mathrm{BH}-1$} & 136.5 & 6.46 & 5.16 & 3.48 & 0.74 & -0.58 & -0.08 & 6.83 & 4.99 & 3.29 \\
\hline & 139.0 & 6.56 & 5.28 & 3.55 & 0.74 & -0.60 & -0.08 & 6.93 & 5.11 & 3.35 \\
\hline & 141.1 & 6.65 & 5.37 & 3.61 & 0.73 & -0.61 & -0.08 & 7.01 & 5.21 & 3.41 \\
\hline & 149.5 & 6.99 & 5.75 & 3.84 & 0.71 & -0.66 & -0.08 & 7.34 & 5.61 & 3.63 \\
\hline & 153.0 & 7.13 & 5.91 & 3.94 & 0.70 & -0.68 & -0.08 & 7.48 & 5.77 & 3.72 \\
\hline & 160.3 & 7.42 & 6.24 & 4.14 & 0.68 & -0.72 & -0.08 & 7.77 & 6.12 & 3.91 \\
\hline \multirow[t]{8}{*}{ BH-2 } & 121.0 & 5.84 & 4.47 & 3.04 & 0.79 & -0.49 & -0.07 & 6.22 & 4.25 & 2.88 \\
\hline & 126.5 & 6.06 & 4.71 & 3.20 & 0.77 & -0.52 & -0.07 & 6.44 & 4.51 & 3.03 \\
\hline & 129.0 & 6.16 & 4.83 & 3.27 & 0.76 & -0.54 & -0.07 & 6.54 & 4.63 & 3.09 \\
\hline & 134.5 & 6.38 & 5.07 & 3.42 & 0.75 & -0.57 & -0.07 & 6.75 & 4.89 & 3.24 \\
\hline & 140.0 & 6.61 & 5.32 & 3.58 & 0.73 & -0.60 & -0.08 & 6.97 & 5.15 & 3.38 \\
\hline & 144.0 & 6.77 & 5.50 & 3.69 & 0.72 & -0.63 & -0.08 & 7.13 & 5.34 & 3.49 \\
\hline & 148.5 & 6.95 & 5.70 & 3.81 & 0.71 & -0.65 & -0.08 & 7.30 & 5.56 & 3.60 \\
\hline & 151.5 & 7.07 & 5.84 & 3.90 & 0.70 & -0.67 & -0.08 & 7.42 & 5.70 & 3.68 \\
\hline \multirow[t]{4}{*}{ BH-3 } & 138.5 & 6.54 & 5.25 & 3.53 & 0.74 & -0.60 & -0.08 & 6.91 & 5.08 & 3.34 \\
\hline & 143.5 & 6.75 & 5.48 & 3.67 & 0.72 & -0.62 & -0.08 & 7.11 & 5.32 & 3.47 \\
\hline & 145.5 & 6.83 & 5.57 & 3.73 & 0.72 & -0.64 & -0.08 & 7.19 & 5.42 & 3.53 \\
\hline & 149.0 & 6.97 & 5.73 & 3.83 & 0.71 & -0.66 & -0.08 & 7.32 & 5.58 & 3.62 \\
\hline
\end{tabular}


Both HF and HTPF were performed in multiple inclined boreholes at underground cavern.

3-D stress inversion code integrating the data from HF and HTPF was developed.

Relationship between fracture pattern and reopening pressure was analyzed.

Scatter analysis of the integrated stress inversion was carried out. 


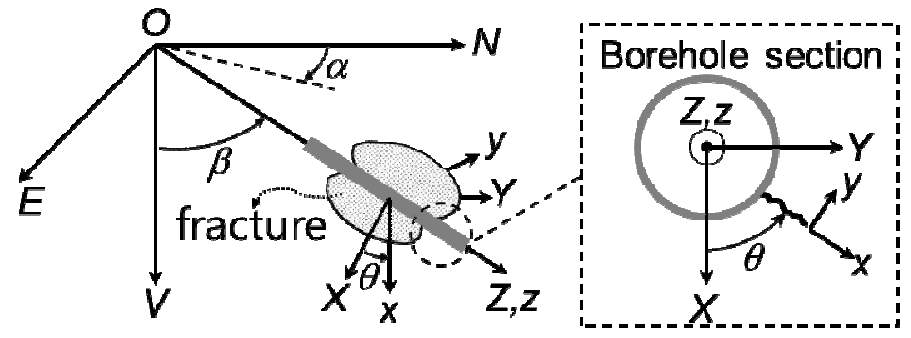

(a) Longitudinal fracture

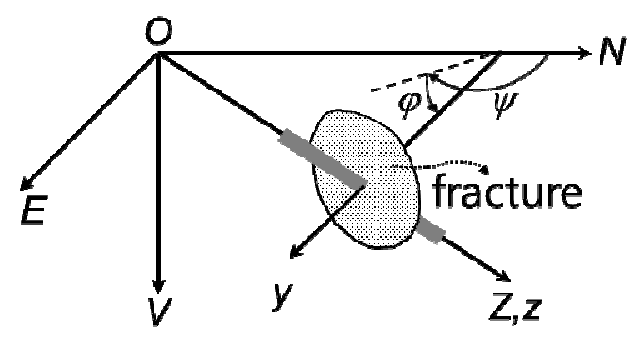

(b) Transverse fracture

Fig. 1. Configuration of fracture pattern and coordinate system.

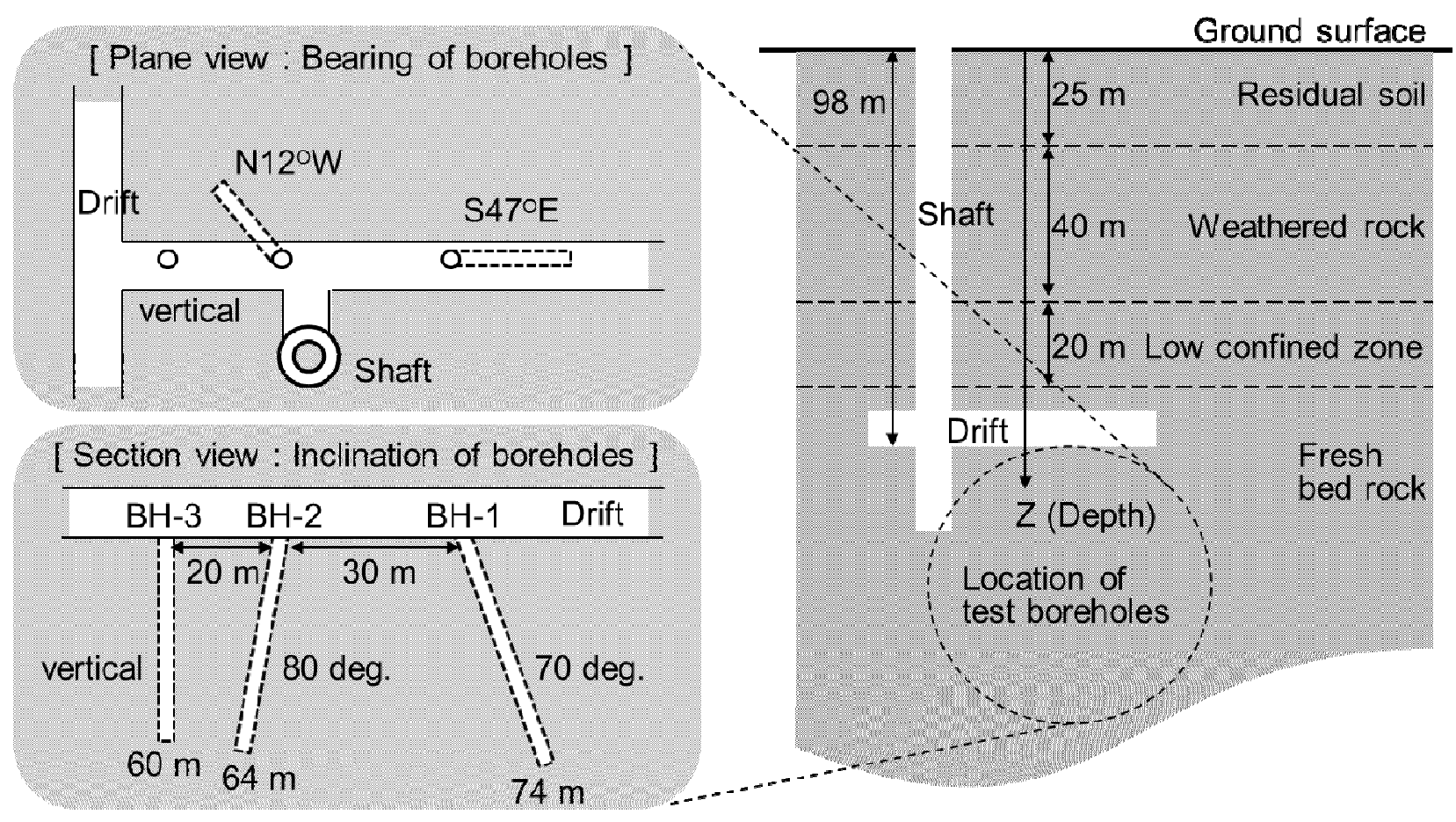

Fig. 2. Stratigraphy of the test site and the location of boreholes. 


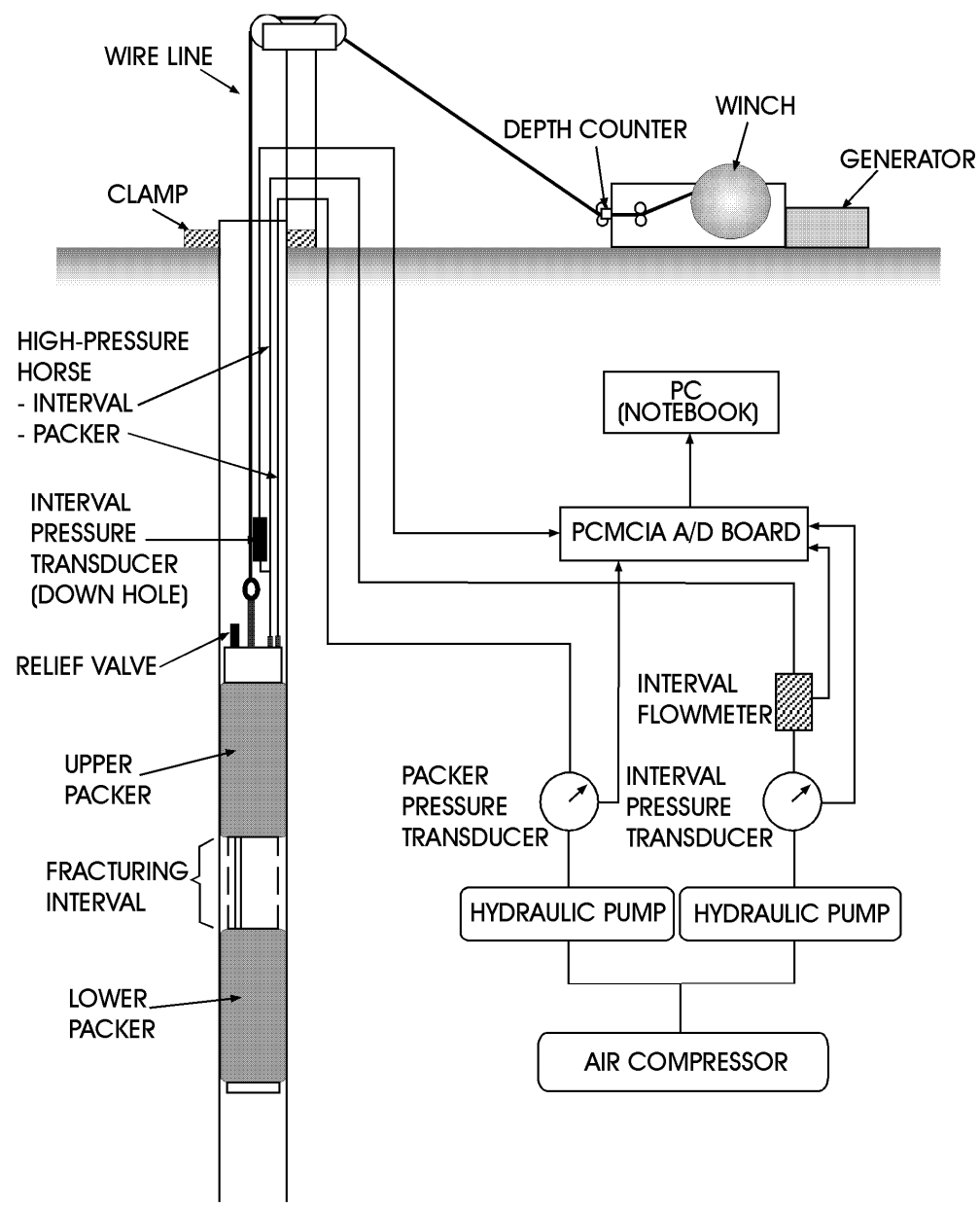

Fig. 3. Schematic view of wireline type hydraulic fracturing system.

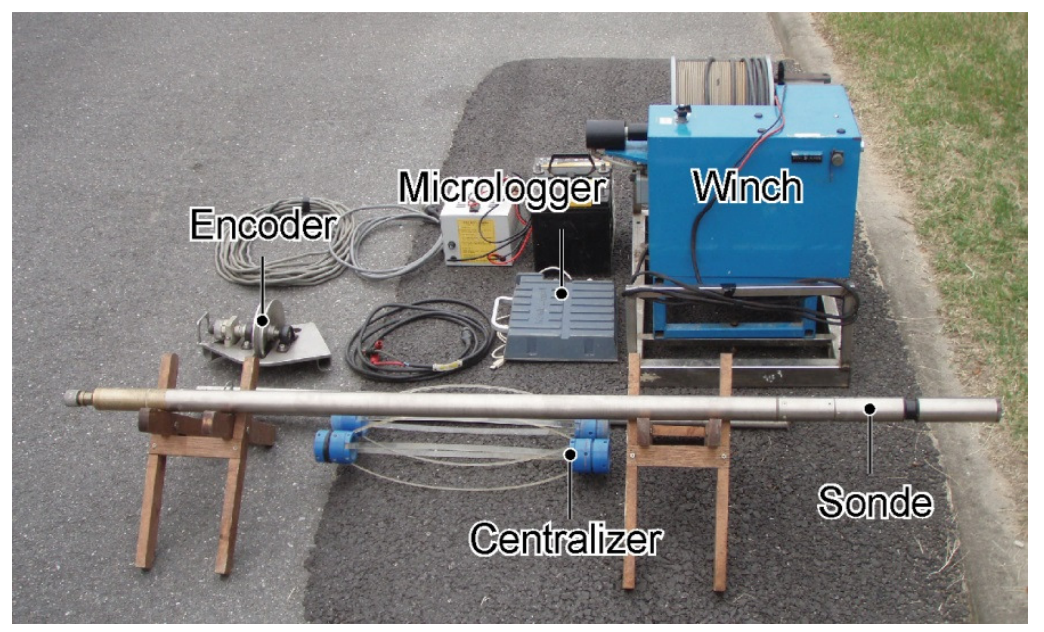

Fig. 4. General view of acoustic borehole televiewer. 

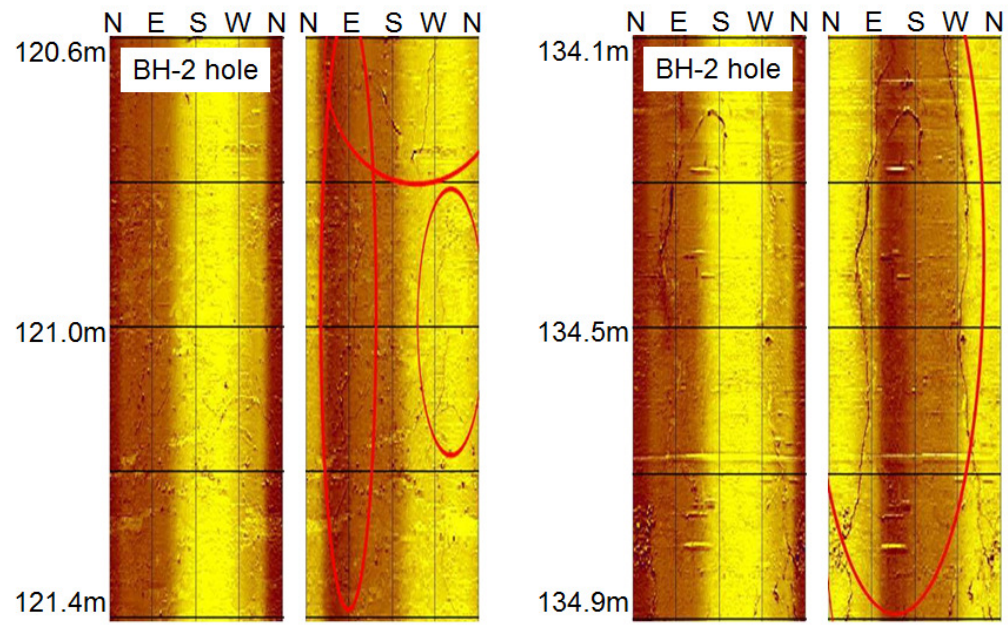

(a) Newly induced fracture

(b) Slightly open pre-existing fracture

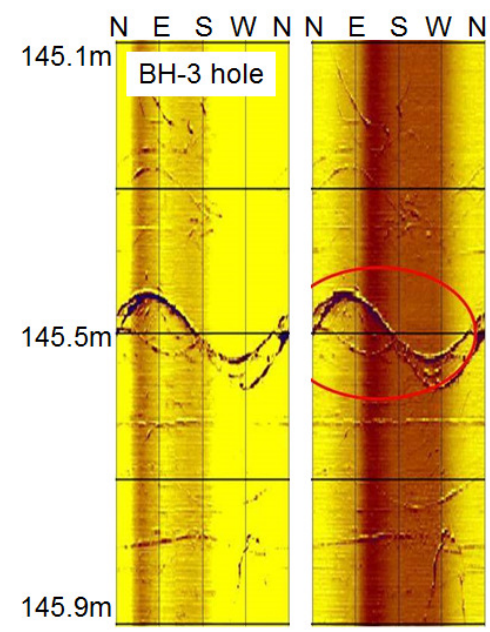

(c) Wide open pre-existing fracture

Fig. 5. Fracture traces on the borehole wall by an acoustic borehole televiewer. In a pair of each image, left is before test and right is after test. Fracture traces are indicated within red circles.
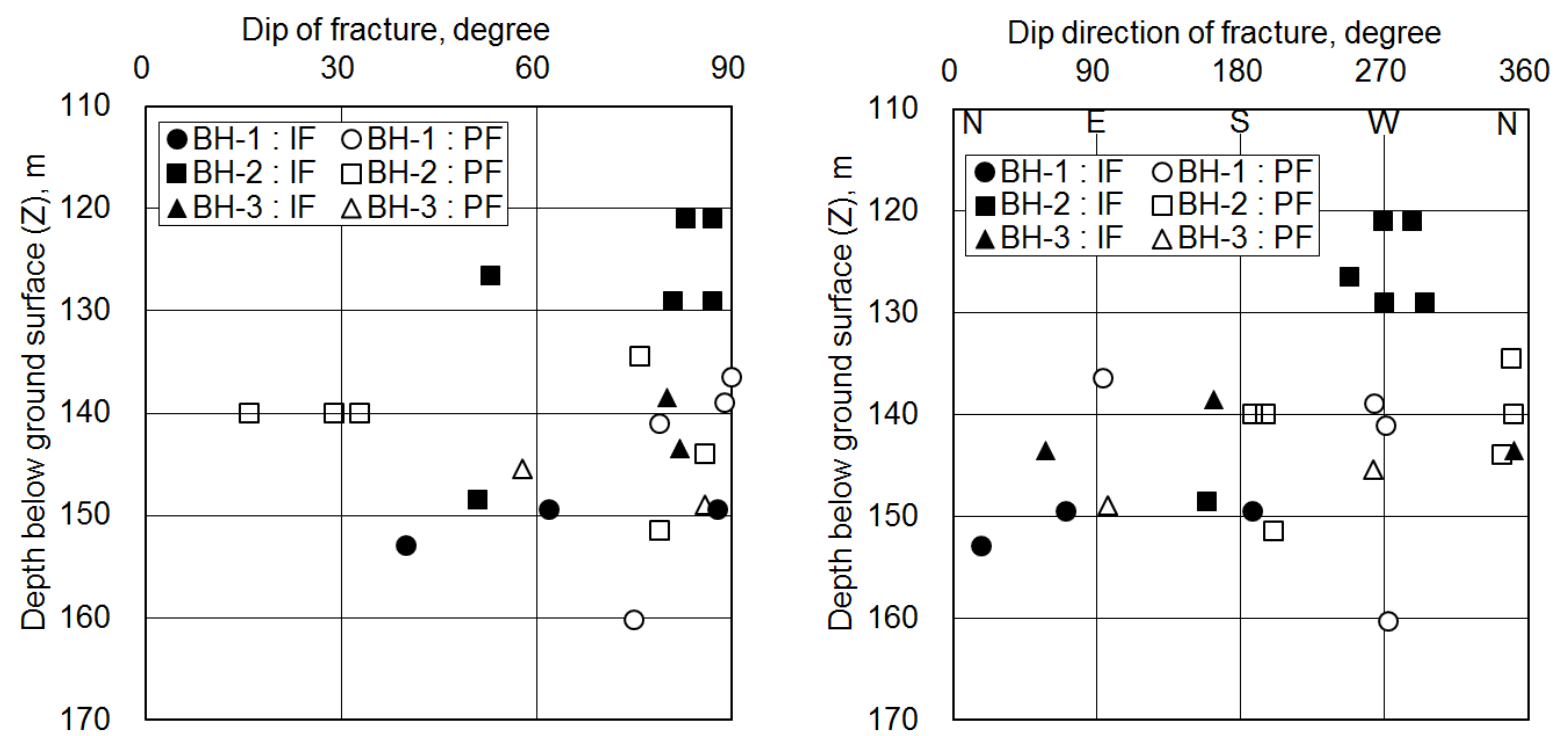

Fig. 6. Distribution of orientations (dip and dip direction) of fracture planes. IF : induced fracture, PF : pre-existing fracture. 

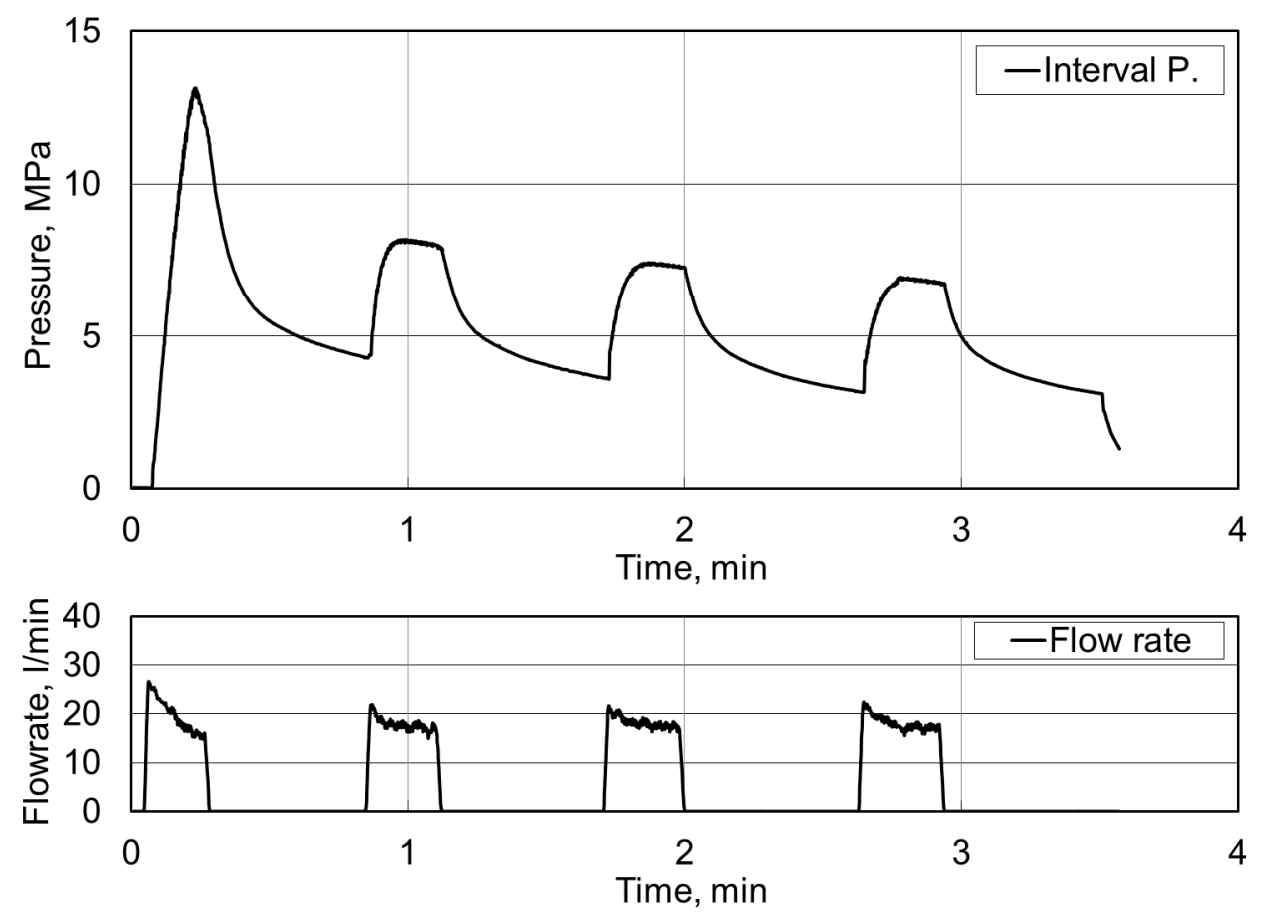

(a) Pressure versus time record by HF
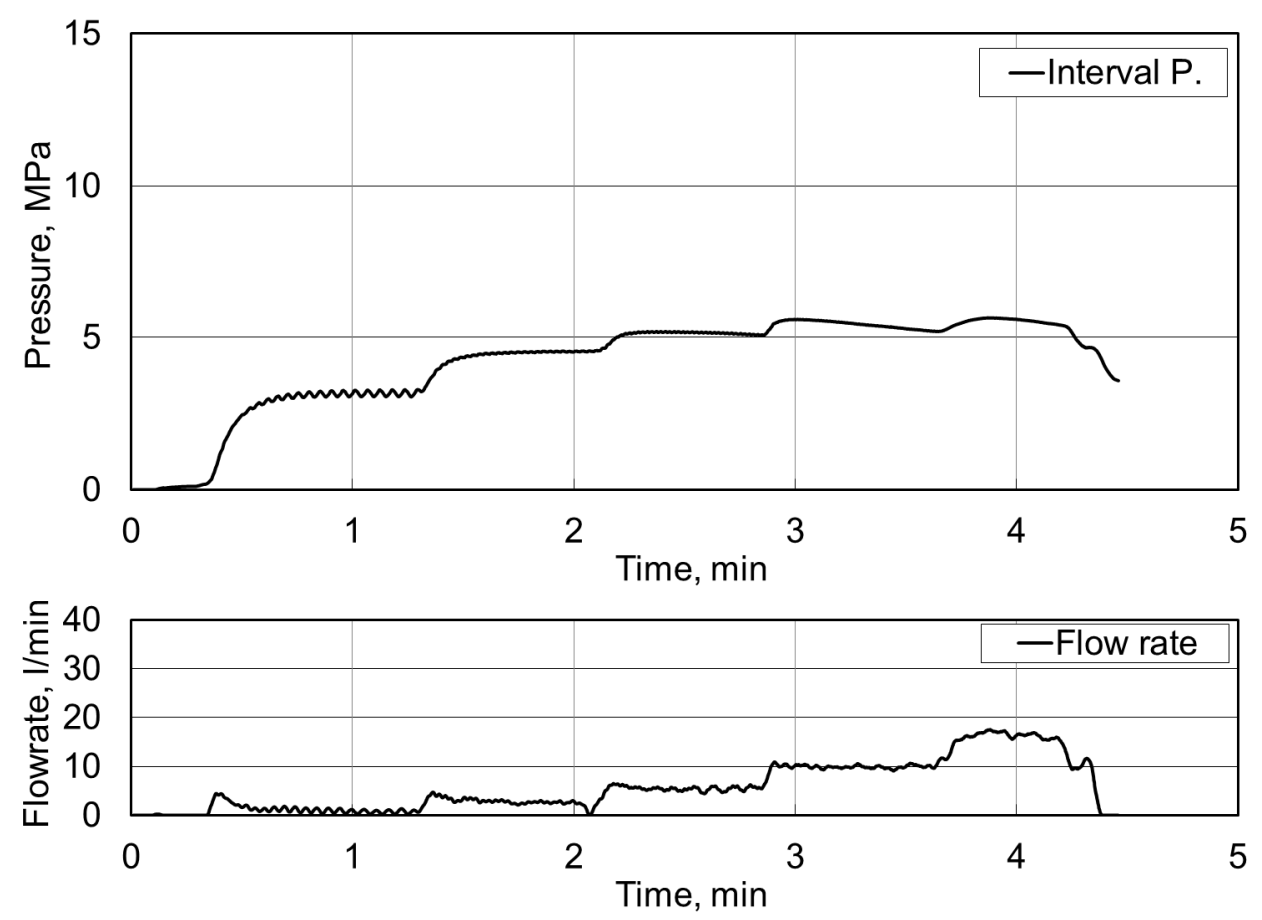

(b) Pressure and flow rate versus time record by HTPF

Fig. 7. Typical records obtained from field measurements by HF and HTPF (BH-2, $121.0 \mathrm{~m})$. 


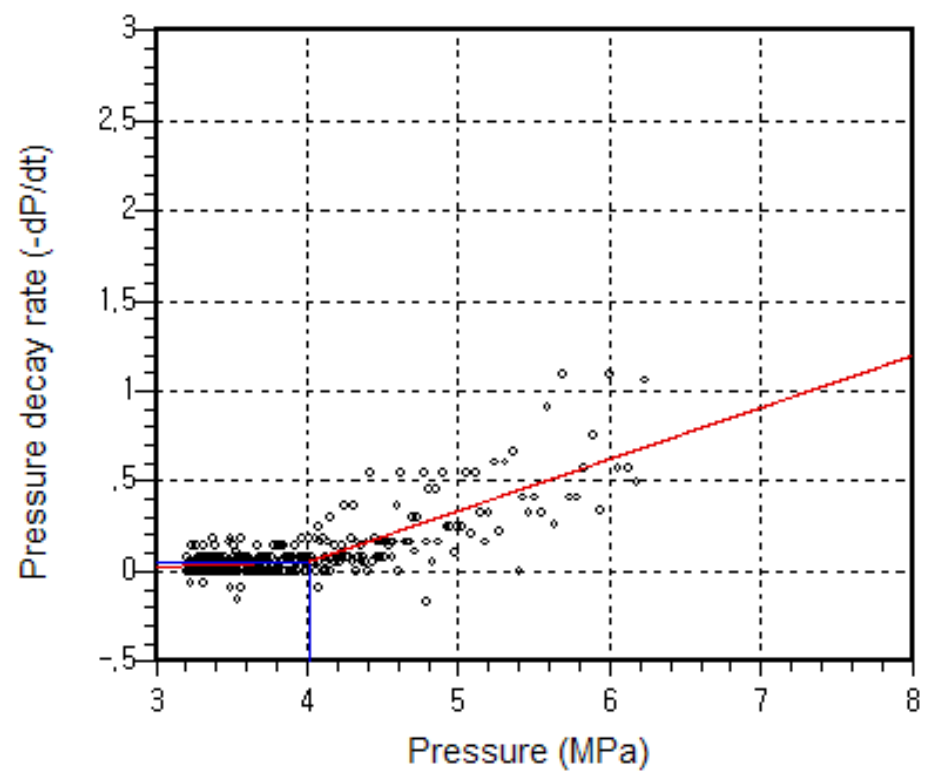

(a) Shut-in pressure

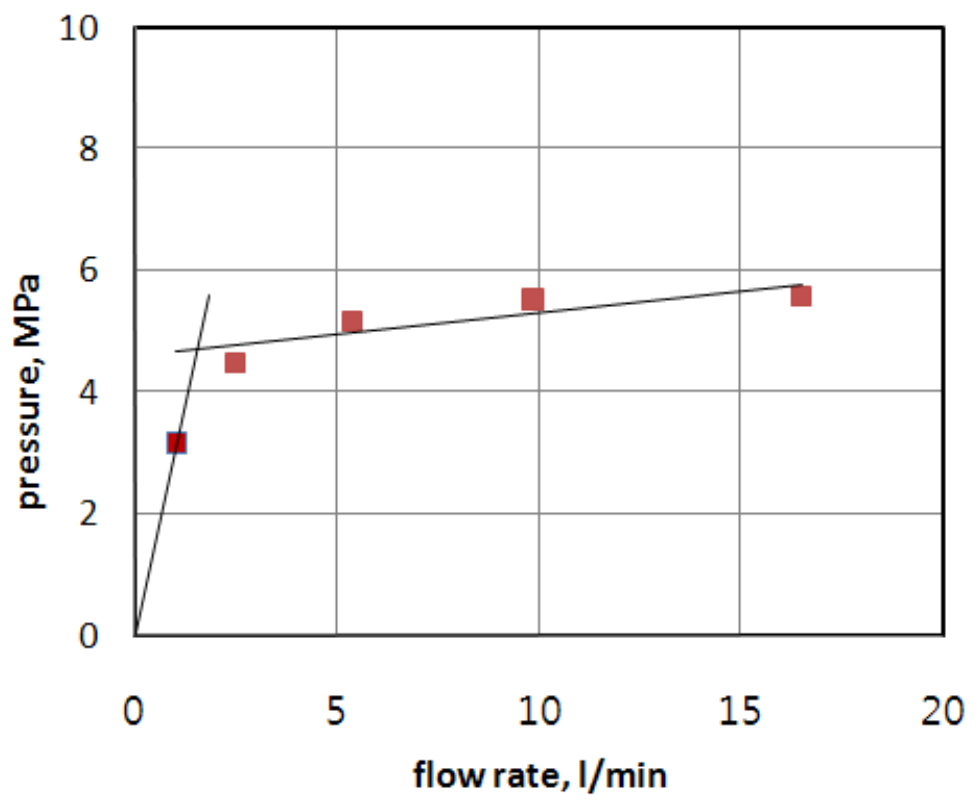

(b) Fracture normal pressure

Fig. 8. Determination of (a) shut-in pressure $P_{s}$ by bilinear pressure-decay-rate method and (b) fracture normal pressure $P_{n}$ by pressure-versus-flowrate method (BH-2, $\left.121.0 \mathrm{~m}\right)$. 


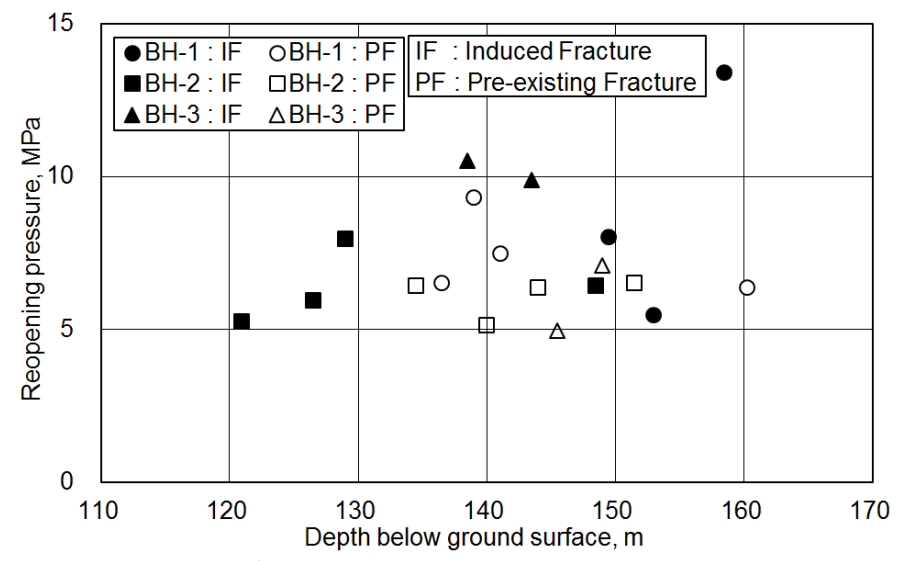

(a) Reopening pressure

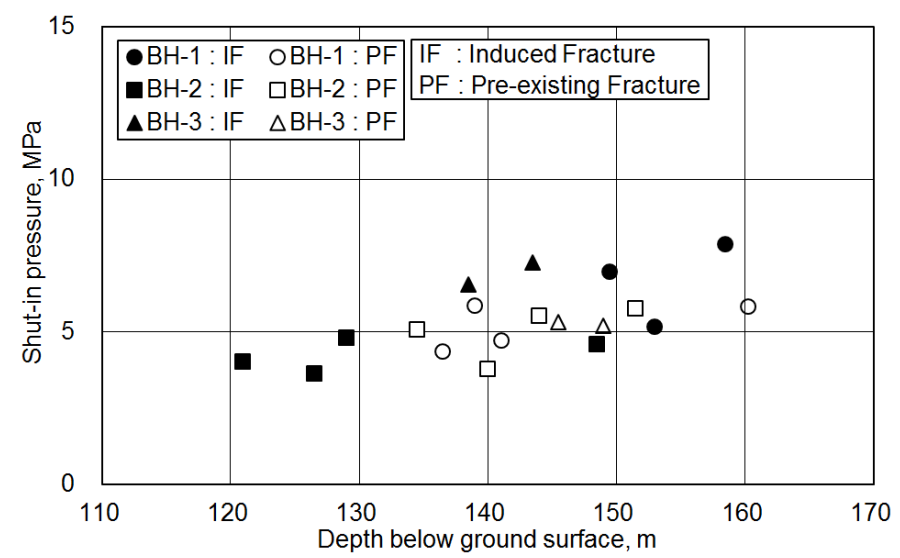

(b) Shut-in pressure

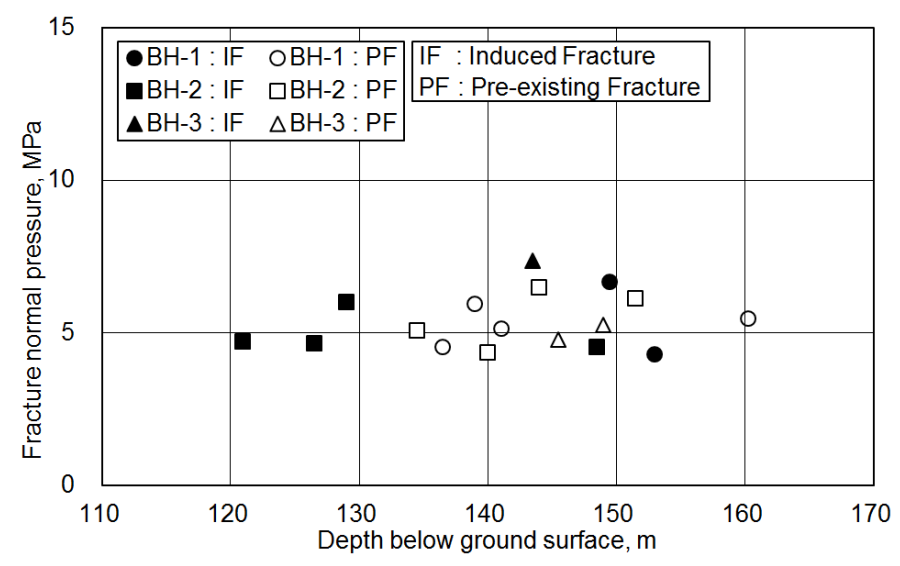

(c) Fracture normal pressure

Fig. 9. Pressure parameters determined by statistical techniques from field measurement records. 


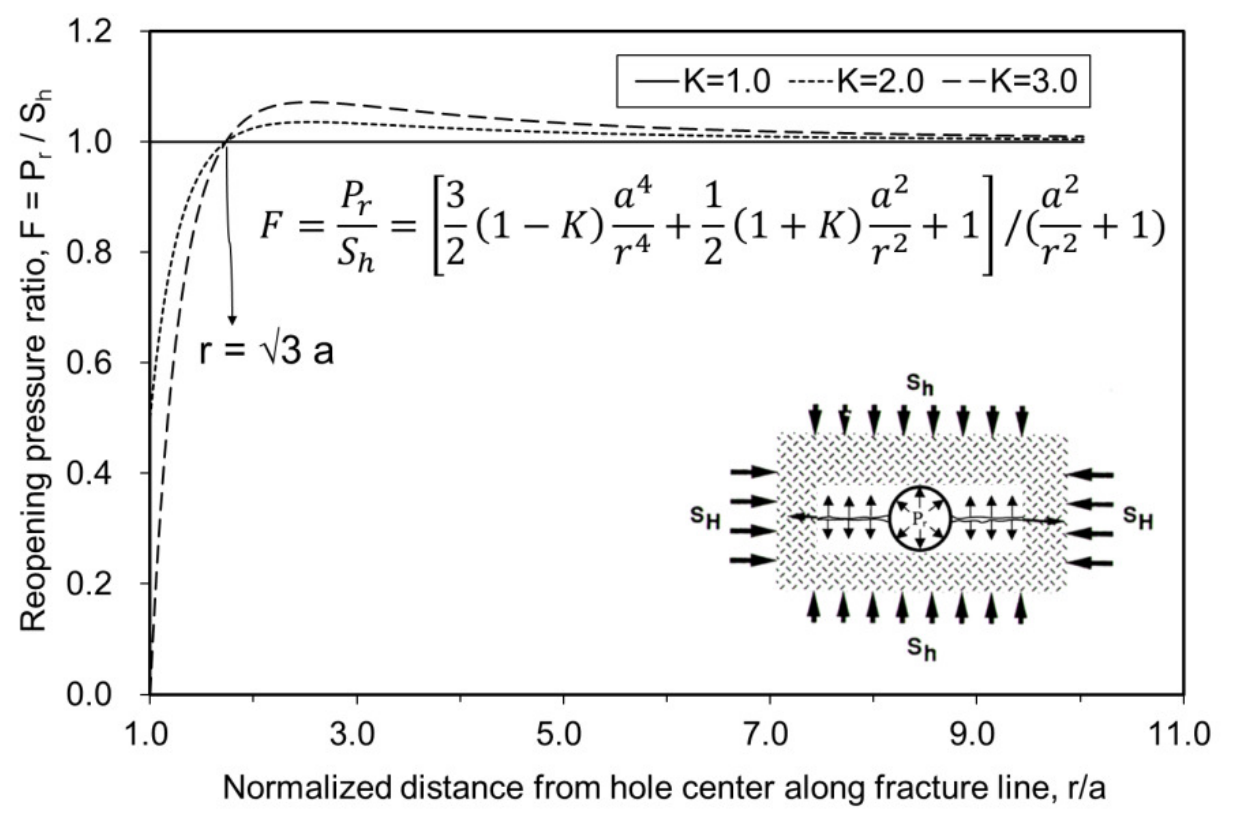

Fig. 10. Analytical reopening pressure according to the open tip length of a pre-existing fracture model.
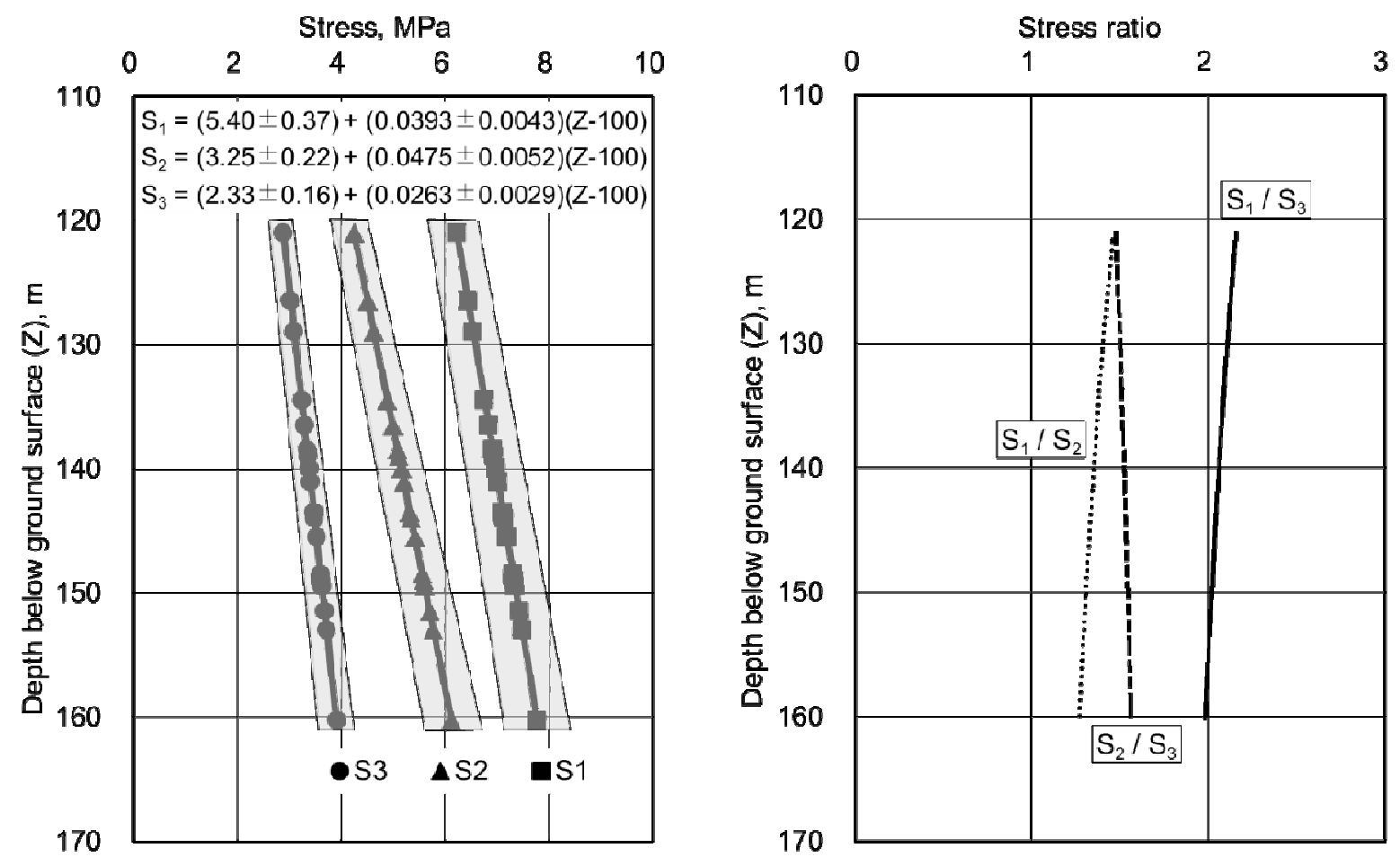
(a) Principal stresses
(b) Stress ratios

Fig. 11. Trends of principal stresses and stress ratios with depth. 


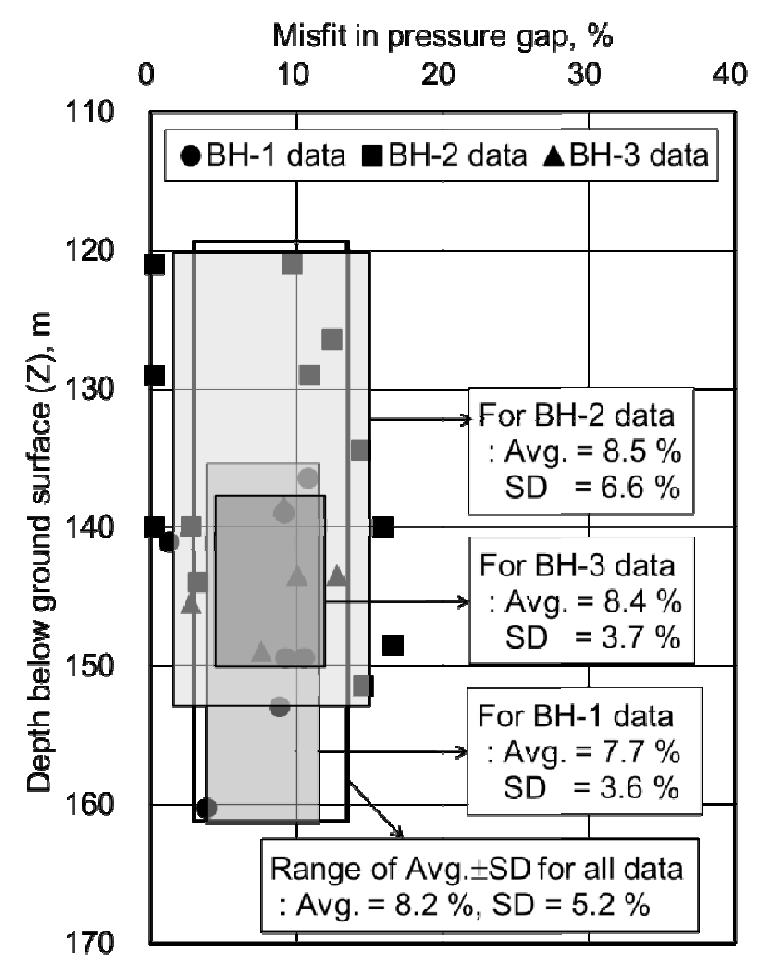

Fig. 12. Comparison of the scatter between the integrated inversion result for combining all boreholes and the field measurement data for each borehole.
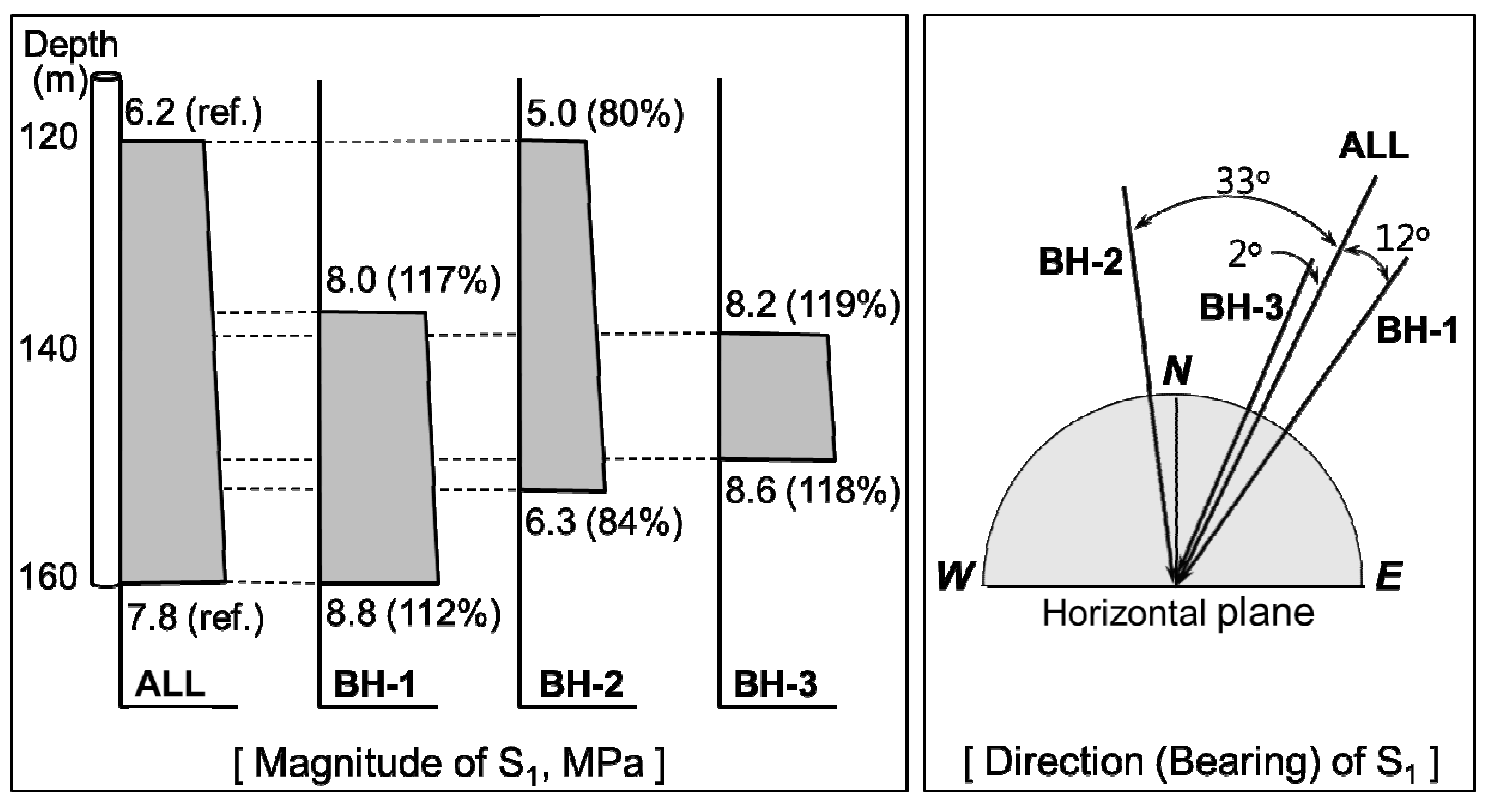

Fig. 13. Comparison of stress inversion results for individual borehole and for combining all boreholes. 


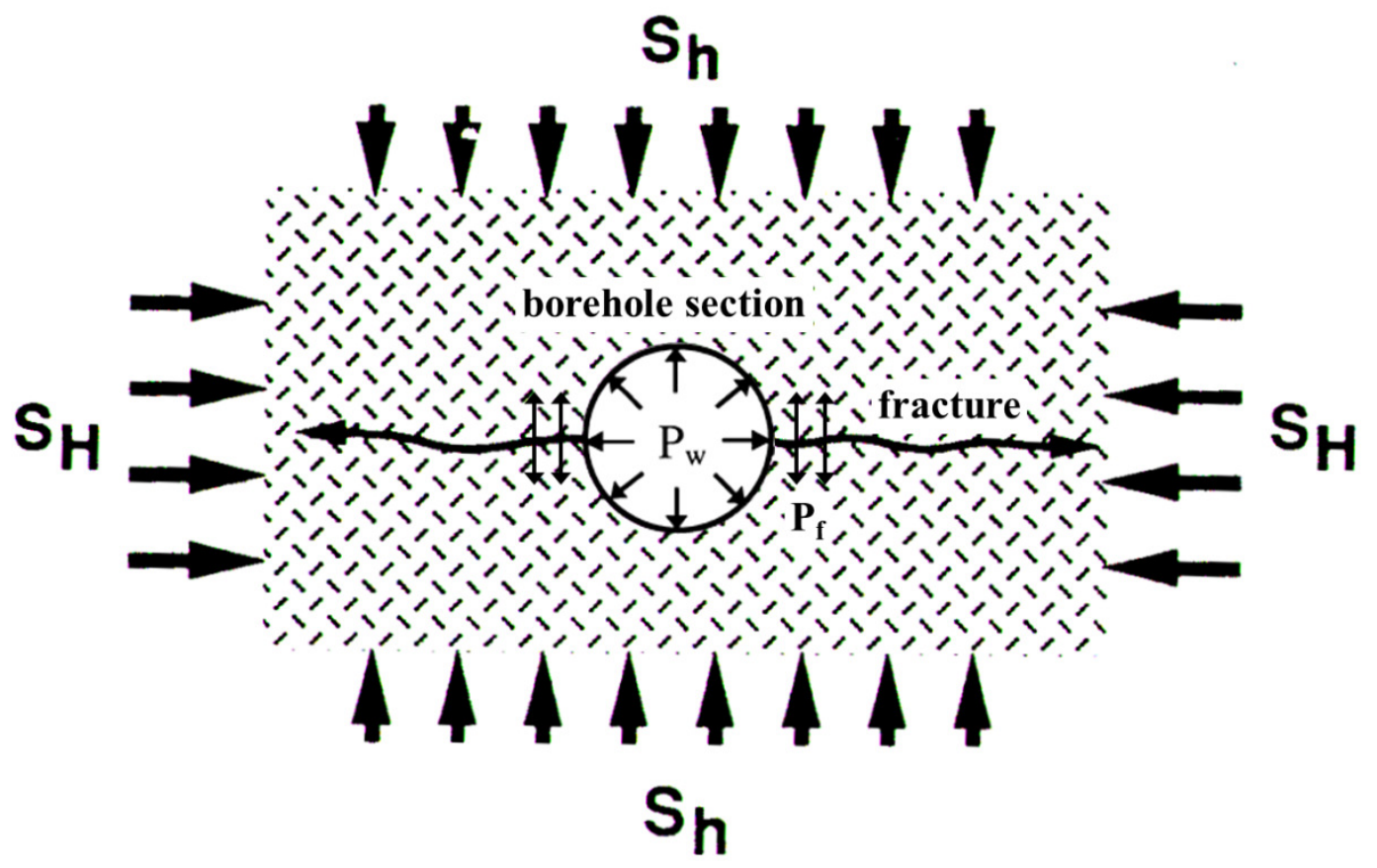

Fig. B.1. Stress distribution around a borehole with a pre-existing fracture model. 